\title{
Evidências das forças causais críticas dos processos de institucionalização e desinstitucionalização em artefatos da contabilidade gerencial
}

The critical casual force disclosures of the institutionalization and deinstitutionalization processes in managerial accounting artefacts

Evidencia de la fuerzas causales críticas de los procesos de institucionalización y desinstitucionalización en artefactos de la contabilidad de gestión

\section{Paschoal Tadeu Russo}

Doutor em Controladoria e Contabilidade pela Universidade de São Paulo

Professor do Mestrado Profissional em Controladoria e Finanças da FIPECAFI

Endereço: Rua Maestro Cardim, n॰ 1170 - Bela Vista

CEP: 01.323-001 - São Paulo/SP - Brasil

E-mail: ptrusso@terra.com.br

Telefone: + 55 (11) 2184-2000

\section{Claudio Parisi}

Doutor em Controladoria e Contabilidade pela Universidade de São Paulo

Professor do Mestrado em Ciências Contábeis da FECAP

Endereço: Avenida da Liberdade, n॰ 532 - Liberdade

CEP: 01.502-001 - São Paulo/SP - Brasil

E-mail: claudio.parisi@uol.com.br

Telefone: + 55 (11) 3272-2301

\section{Carlos Alberto Pereira}

Doutor em Controladoria e Contabilidade pela Universidade de São Paulo

Professor do Programa de Pós-Graduação em Controladoria e Contabilidade da Universidade de São Paulo

Endereço: Avenida Professor Luciano Gualberto, n॰ 908 - Butantã

CEP: 05.508-010 - São Paulo/SP - Brasil

E-mail: cap@usp.br

Telefone: +55 (11) 3091-5820

Artigo recebido em 15/10/2015. Revisado por pares em 01/06/2016. Reformulado em 15/08/2016. Recomendado para publicação em 30/08/2016 por Sandra Rolim Ensslin (Editora Científica). Publicado em 17/12/2016. 


\title{
Resumo
}

O objetivo da pesquisa foi conhecer as forças causais críticas para os processos de institucionalização e desinstitucionalização que agem sobre os artefatos da contabilidade gerencial em uma concessionária brasileira de serviços públicos que atua em território brasileiro. Trata-se de uma pesquisa qualitativa através da investigação por meio de entrevista semiestruturada realizada em uma empresa de água e esgoto, a respeito de uma prática de planejamento que no estudo foi denominada "Processo de Gestão Integrado" (PGI). Foram aplicadas as técnicas de análise de conteúdo e análise do discurso. A pesquisa permitiu a constatação de que o PGI se encontrava em um processo de desinstitucionalização devido à perda do patrocínio da alta administração para o seu uso como prática de planejamento da organização, além do surgimento de um novo artefato que foi posicionado como concorrente do PGI. Foi possível conhecer um conjunto de 24 (vinte e quatro) elementos correlatos da Teoria Institucional, os quais atuam como forças causais do processo de institucionalização e desinstitucionalização do PGI.

Palavras-chave: Contabilidade Gerencial; Teoria Institucional; Forças Causais Críticas

\begin{abstract}
The research objective was to get to know the causal forces that are critical to the institutionalization and deinstitutionalization processes that act on the managerial accounting artifacts in Brazilian public service dealerships that operate in Brazil. It is a qualitative research led by semi-structured interviews in a water and sewage company over a planning practice that was denominated in the Integrated Management Process (PGI) study. It was applied content analysis and speech analysis techniques. I was also possible to identify that the PGI was in a deinstitutionalization process due to the sponsorship loss of the top management for its use and the coming up of a new artifact that was positioned as a competitor of PGI. It was possible to know a set of twenty-four elements correlated to Institutional Theory that act as the institutionalization and deinstitutionalization causal force processes of PGI.
\end{abstract}

Keywords: Managerial Accounting, Institutional Theory, Critical Causal Forces

\section{Resumen}

El objetivo de la investigación fue comprender las fuerzas causales que son críticas para los procesos de institucionalización y desinstitucionalización que actúan sobre los artefactos de la contabilidad de gestión, en un concesionario brasileño de servicios públicos que opera localmente. Se trata de una investigación cualitativa mediante la realización de entrevistas semi-estructuradas en una compañía de agua y alcantarillado, acerca de una práctica de planificación que se denomina en el estudio Proceso de Gestión Integrado (PGI). Se aplicaron las técnicas de análisis de contenido y análisis del discurso. Fue posible identificar que el PGI se encontraba en un proceso de desinstitucionalización debido a la pérdida de apoyo por parte de la alta dirección y el surgimiento de un nuevo dispositivo que se ha considerado un competidor del PGI. Fue posible revelar un conjunto de veinticuatro elementos relacionados a la Teoría Institucional que actúan como fuerzas causales del proceso de institucionalización y desinstitucionalización del PGI.

Palabras clave: Contabilidad de Gestión; Teoría Institucional; Fuerzas Causales Críticas 


\section{Introdução}

A Teoria Institucional tem se destacado por oferecer uma abordagem diferenciada para os estudos sobre as mudanças em contabilidade gerencial (BURNS; SCAPENS, 2000). A Nova Sociologia Institucional (New Institutional Sociology - NIS) é uma de suas vertentes que estuda as relações entre as organizações e o ambiente no qual estão inseridas. (GUERREIRO et al., 2005; STEEN, 2005) A NIS também estuda os elementos institucionais, entre os quais se enquadram as práticas e os modelos desenvolvidos e estudados em contabilidade gerencial, tais como o orçamento, o custeio ABC e o Balanced Scorecard BSC (ITTNER; LARCKER; MEYER, 2003). Estes elementos, no entendimento de Dimaggio e Powelll (1983), surgem de dentro da organização ou da imitação de outras organizações similares. Eles são transmitidos e mantidos nas organizações por longos períodos e podem se tornar instituições organizacionais, vindo a ser considerados taken-for-granted. Nessa trajetória se dá seu processo de institucionalização.

Para Zucker (1977), elementos institucionais surgem e podem ser percebidos diferentemente em função das ações sociais que eles desencadeiam, e essas ações podem ser mais ou menos percebidas porque os elementos podem ser encontrados em diferentes graus (estágios) de institucionalização. Tolbert e Zucker (1999) descrevem os estágios préinstitucionalização, semi-institucionalização e total institucionalização como etapas do processo de institucionalização, sendo que a última, já quando a instituição está consolidada, tem condições de promover o maior nível de mudanças sociais. A criação de novas instituições demanda um esforço considerável da ação humana para a sua produção e manutenção (TOLBERT; ZUCKER, 1999, p. 203).

Grande parte dos teóricos organizacionais tem analisado estruturas formais como estáticas, focando seus recursos em um determinado ponto no tempo, contrariamente aos estudos de Meyer e Rowan (1977) e de Tolbert e Zucker (1983). A visão de estruturas formais e estáticas está associada à percepção de passividade nos processos de institucionalização. Tal percepção pode estar errada, uma vez que algumas organizações e atores, em determinadas situações, precisam se conformar a mandatos institucionais e à limitação de recursos, o que pode não ocorrer de forma passiva. Os artefatos e atores organizacionais podem estar inseridos em contextos onde o poder e o autointeresse, de dentro e de fora da organização, podem agir de forma determinante (COVALESKI; DIRSMITH, 1988).

Diversas pesquisas vêm sendo realizadas com o objetivo de entender e evidenciar os benefícios advindos do uso da Teoria Institucional para a compreensão dos processos de mudança em contabilidade gerencial, tais como:

- Guerreiro et al. (2005); Thornton; Jones e Kury, 2005; Guerreiro; Frezatti; Casado (2006); Carvalho, Vieira e Silva (2012); Russo et al. (2012); Lounsbury e Boxenbaum (2013); Smets e Jarzabkowski (2013); Jones e Raey (2015); Popik e Lavarda (2015); Russo (2015); Svenningsen, Boxenbaum e Ravasi (2016), que analisam as fundamentações da Teoria Institucional para seu uso em contabilidade gerencial;

- Zan (2006); Frezatti, Aguiar e Resende (2007); Eberle e Colauto (2014); Brizola et al.(2015); Wanderley e Soeiro (2016), que analisam mudanças em sistemas de custos e orçamentos e BSC;

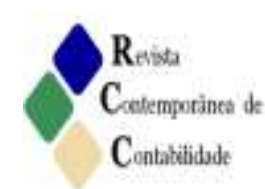


- Guerreiro, Pereira e Frezatti (2008); Reis (2008) e Rezende (2009); Guerreiro, Rodrigues e Craig (2012); Wrubel, Toigo e Lavarda (2014); Casagrande e Lavarda (2015); Rodrigues e Soeiro (2016); Miranda e Araújo (2016), que analisam mudanças na contabilidade gerencial de instituições financeiras, contabilidade financeira e estruturas de governança.

O sentido de institucional, segundo Zucker (1987), está associado a regras - como padrões sociais de ações organizadas - e à percepção de algo que está inserido nas estruturas formais e que não está vinculado a atores ou situações particulares. Já para Tolbert e Zucker (1999) o processo de institucionalização se dá por meio de um conjunto de forças causais, que na visão destas autoras são críticas e inerentes ao processo de institucionalização (internas e externas à organização) desenvolvido por elas mesmas. Segundo elas, estas forças são responsáveis pela mudança dos estágios/níveis de institucionalização, a saber: mudanças tecnológicas, legislação, forças de mercado, monitoramento organizacional, teorização, processo de difusão, impactos positivos, resistências de grupos de interesse, defesa de grupos e heterogeneidade dos atores. Estas forças causais atuam sobre os atores, organizações e artefatos, contribuindo para a mudança dos estágios de institucionalização.

Sob a ótica da NIS, no contexto institucional de uma organização evidenciar o conjunto de forças causais críticas que atuam sobre os atores, artefatos e a organização pode ajudar a compreender como artefatos associados ao processo de gestão podem ser institucionalizados, ou mesmo desinstitucionalizados. Entende-se que em cada contexto organizacional emergem forças diferentes que podem interferir no processo de institucionalização e são particulares do contexto de cada organização e do conjunto de atores organizacionais a ela relacionados (CARVALHO; VIEIRA; SILVA, 2012). Desta forma, parte-se do pressuposto que o conjunto de forças causais críticas apresentadas por Tolbert e Zucker (1999) não necessariamente refletem a realidade das forças existentes para estudos em organizações brasileiras.

Dentro deste enfoque, este trabalho se propõe a responder a seguinte questão de pesquisa: quais são as forças causais críticas para os processos de institucionalização e desinstitucionalização que agem sobre os artefatos de contabilidade gerencial em uma concessionária de serviços públicos que opera no Brasil?

Como objetivo principal da pesquisa pretende-se conhecer as forças causais que são críticas para os processos de institucionalização e desinstitucionalização que agem sobre os artefatos de contabilidade gerencial em uma concessionária brasileira de serviços públicos, que atua em território brasileiro. Como objetivo secundário, por meio de uma revisão teórica pretende-se identificar, na Teoria Institucional, elementos que possibilitem a ampliação do conhecimento sobre quais são e como atuam as forças causais que são críticas para os processos de institucionalização e desinstitucionalização.

Para tanto, a presente pesquisa foi desenvolvida a partir da possibilidade de se utilizar uma ampla base de dados que foi gerada para uma outra pesquisa, de maior amplitude, que estudava processos de mudança em contabilidade gerencial em uma grande empresa concessionária de serviços públicos de capital misto. Desta base de dados foram disponibilizados, para esta pesquisa, os textos das transcrições de quatro entrevistas (mais de 100 (cem) páginas) realizadas com 4 (quatro) executivos responsáveis pelo processo de mudança no contexto da contabilidade gerencial daquela organização, além de aproximadamente 300 (trezentos) documentos utilizados naquele processo, produzidos pela organização estudada. 
A principal contribuição deste trabalho é a evidenciação - por meio da análise de conteúdo e da análise de discurso - da existência de variedade e quantidade de tipos de forças causais críticas - e de seus amplos alcances - que agem ativamente sobre os processos responsáveis pela institucionalização ou desinstitucionalização de instrumentos da contabilidade gerencial. Tais forças, neste trabalho, emergem da análise de conteúdo e da análise de discurso que ocorrem sob a ótica da NIS, da singularidade da visão de cada entrevistado que, à luz da teoria, proporciona a evidenciação de aspectos teóricos relevantes, que vão se confirmando à medida que as novas entrevistas são analisadas e confirmam os mesmos elementos (BARDIN, 2009). A identificação de uma grande quantidade de tipos de forças causais é um achado relevante desta pesquisa, pois amplia o entendimento original que vem de uma proposição das forças causais críticas de autoria de Tolbert e Zucker (1999, p.211), conforme anteriormente mencionado, sob a denominação de mudanças tecnológicas, legislação, forças de mercado, monitoramento organizacional, teorização, processo de difusão, impactos positivos, resistências de grupos de interesse, defesa de grupos e heterogeneidade dos atores.

A pesquisa se justifica pela ênfase que é dada à análise dos processos de mudança em contabilidade gerencial, notadamente sob a ótica da Nova Sociologia Institucional - NIS, bem como à possibilidade de expandir-se a percepção sobre a abrangência e o alcance das forças causais que são críticas para os processos de institucionalização e desinstitucionalização de artefatos da contabilidade gerencial em uma organização de grande porte e com alta representatividade econômica e social.

\section{Referencial Teórico}

A contabilidade gerencial tem sido pesquisada nas últimas décadas por diversos estudiosos, tanto no Brasil quanto no exterior. Nota-se a evolução das práticas de contabilidade gerencial ao longo do tempo observando-se o relatório da International Federation of Accountants - IFAC (1998). Atualmente, destacam-se as pesquisas sobre artefatos de contabilidade gerencial. (SOUTES, 2006; FREZATTI; RELVAS; JUNQUEIRA, 2010; BEUREN; RENGEL; RODRIGUES JUNIOR, 2015; FREZATTI; BARROSO; CARTER, 2015) Guerreiro, Cornachione Jr. e Soutes (2011) definem artefatos de contabilidade gerencial como "modelos de gestão, sistemas de gestão, sistemas de informação e conceitos de avaliação de desempenho que possam ser utilizados por profissionais da contabilidade gerencial no exercício de suas funções".

No âmbito deste trabalho, assume-se como artefato objeto de estudo o processo de gestão integrada de uma empresa concessionária de serviços de água e esgoto, aderente à proposta de Parisi (2011). Desdobrando-se este processo em seus elementos é possível identificar as seguintes práticas de contabilidade gerencial: planejamento contínuo, planejamento estratégico, planejamento operacional, balanced scorecard - BSC, gestão baseada em valor - GBV, gestão de projetos, práticas de priorização de projetos e orçamento empresarial. Estes elementos são comumente pesquisados como artefatos de contabilidade gerencial. (OYADOMARI et al., 2008; FREZATTI; RELVAS; JUNQUEIRA, 2010; FREZATTI et al., 2010; GUERREIRO; CORNACHIONE JUNIOR; SOUTES, 2011)

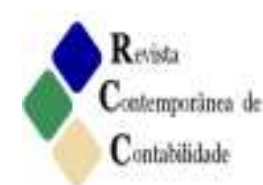


A Teoria Institucional tem sido utilizada porque apresenta uma abordagem diferenciada para os estudos sobre mudanças em contabilidade gerencial. Dada sua amplitude, ela é classificada por Burns e Scapens (2000) em três diferentes vertentes: Nova Economia Institucional (New Institutional Economics - NIE), Velha Economia Institucional (Old Institutional Economics - OIE) e Nova Sociologia Institucional (New Institutional Sociology - NIS). A NIS, vertente que será utilizada nesta pesquisa, tem seu foco nas instituições e microinstituições, e tem sido utilizada para identificar como o processo de mudanças institucionais acontece partindo das relações entre indivíduos no interior das organizações. (GUERREIRO et al., 2005; STEEN, 2005)

Zucker (1977) a existência de autointeresse e necessidade funcional, apesar da passividade dos atores quanto à manutenção das instituições. Para a autora, a sobrevivência das instituições ao longo do tempo pode ser entendida no contexto dos fatores da persistência cultural: transmissão, manutenção e resistência. $\mathrm{O}$ primeiro fator refere-se ao processo de sucessão do uso de geração em geração. O segundo considera que quanto mais tempo de vida tiver uma instituição, maior chance ela terá de continuar existindo; e o último acredita que quanto mais tempo de vida tiver uma instituição, mais resistente a mudanças ela será. $\mathrm{O}$ autor citado acima entende que a institucionalização é uma variável que possibilita compreender os diferentes graus (ou níveis) da persistência observada ou esperada.

Para Meyer e Rowan (1977), estrutura formal é o conjunto das bases para a realização das atividades. Podem ser citadas como exemplos de estruturas formais: escritórios, departamentos, posições e programas. Para esses autores, tais elementos são criados para atender a políticas e objetivos explícitos que formam a base de uma teoria racional de como e para que fim - as atividades são providas juntas. Eles entendem que a estrutura racional formal é assumida como o mais efetivo modo de coordenar e controlar o relacionamento complexo da rede de trabalho envolvida nas técnicas ou atividades de trabalho, o que justifica o fato de que organizações com estruturas formais racionalizadas tendem a se desenvolver. Ainda para esses autores, tais estruturas formais são reforçadas pela opinião pública, pela visão de pessoas influentes que conferem a elas poder e as fazem funcionar de forma impessoal como mitos altamente institucionalizados, que podem, inclusive, integrar as organizações.

Essas estruturas formais racionalizadas surgem em dois contextos: no primeiro, internamente, pela demanda das cadeias de relacionamento local, encorajando estruturas que coordenem e controlem as atividades; no segundo, pela legitimidade que é conferida por meio da interconectividade das relações coletivas na sociedade e das organizações de suas lideranças. (MEYER; ROWAN, 1977) Scott (2001) entende que a legitimidade é conquistada - e consequentemente obtêm-se a institucionalização - quando os atores organizacionais constroem, de forma racional e eficiente, modelos mentais que possibilitam entender o que é eficiente ou não, de acordo com o compartilhamento de um senso comum de significados com os demais atores envolvidos.

Tolbert e Zucker (1999, p. 207) apresentam, na Figura 1 abaixo, as forças causais que são críticas para o processo de institucionalização. 
FIGURA 1- Forças causais que são críticas para o processo de institucionalização

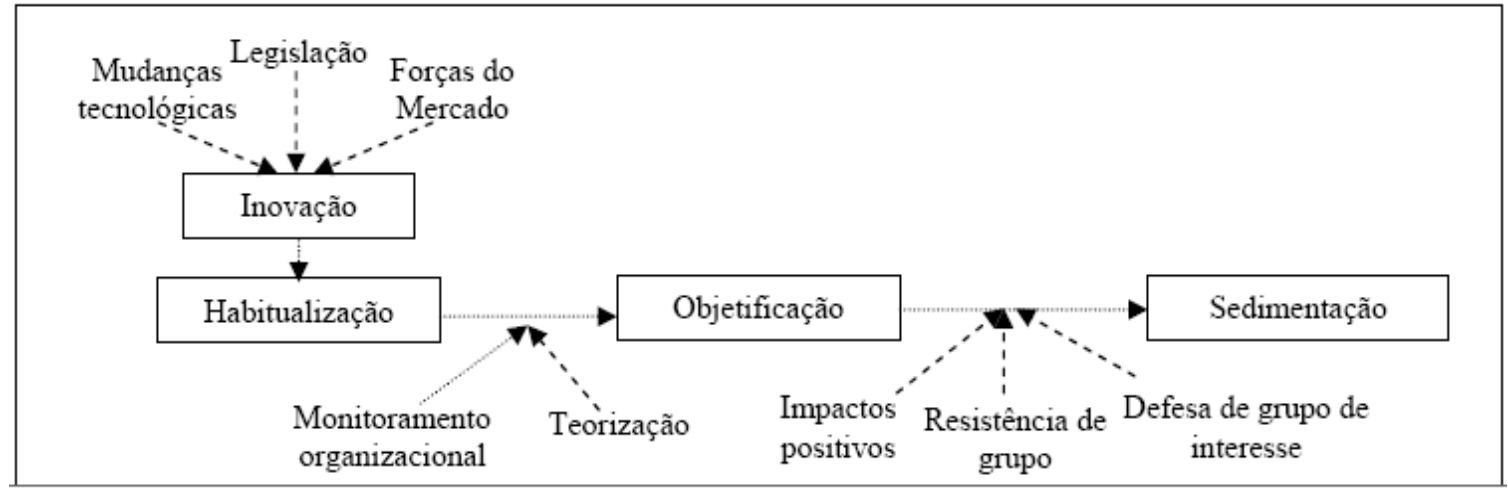

Fonte: Tolbert e Zucker (1999, p. 207)

$\mathrm{Na}$ fase inicial do processo de institucionalização, denominado por Tolbert e Zucker (1999) de habitualização, associado ao estágio de pré-institucionalização, podem existir muitas propostas para a criação de novas estruturas formais por diversos grupos, cada qual formado por atores com características homogêneas, mas sem consenso entre si. Essas novas estruturas são identificadas pelo desejo de imitar estruturas de sucesso identificadas fora da organização e, com isso, resolver problemas específicos sem despender grandes esforços ou investimentos. Como resultado, nesta fase há uma grande variância de modelos e soluções propostas nas organizações e uma alta taxa de fracasso no sucesso da continuidade do uso dessas novas estruturas. Por outro lado, observa-se que à medida que os novos segmentos de mercado vão se consolidando, as empresas que deles fazem parte vão se tornando cada vez mais parecidas umas com as outras, mesmo que tenham origem, história e propósitos diferentes. Isso se dá como consequência desse fenômeno de imitação dessas inovações. Os autores citados acima e Dimaggio e Powell (1983) entendem que esse fenômeno pode ser justificado pelo fato de que essas organizações podem estar submissas a grandes forças de grupos de domínio ou de governos e suas leis. Por fim, é interessante observar que, mesmo que as adoções de inovações pelas organizações sejam motivadas pelo desejo de melhorar os seus desempenhos e aumentar o seu valor, o fato da adoção dessas inovações por grande quantidade de empresas, dadas suas diferenças, não parece ser uma decisão racional. (SELZNICK, 1996; DIMAGGIO; POWELL, 1983)

No entendimento de Tolbert e Zucker (1999, p. 207), à medida que se estabelece o consenso entre os atores de uma organização a respeito do valor de um novo elemento institucional que está se desenvolvendo, identifica-se a ocorrência do processo de objetificação. Este processo está associado ao estágio de semi-institucionalização. Por meio do monitoramento dos resultados das implantações em outras organizações e dos esforços internos empreendidos na construção da nova instituição, toma-se a decisão sobre a favorabilidade de implantar determinados elementos institucionais. Para essas autoras os atores e suas organizações também consideram que os custos de reciclagem de antigas invenções muitas vezes podem ser menores do que os de desenvolver novas.

O êxito do processo de objetificação está associado à adequada realização do processo de teorização. Tal processo compreende duas importantes tarefas: a clara definição de um problema organizacional, reconhecido publicamente, a ser resolvido pelos atores envolvidos; e a justificação do arranjo estrutural formal com bases lógicas por meio de teorias adequadas.

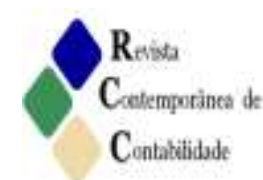


(TOLBERT; ZUCKER, 1999) O processo de objetificação possibilita que as novas instituições possam ser difundidas. A homogeneização das soluções adotadas que pode ser observada nesta fase, na visão de Dimaggio e Powell (1983), é explicada pela força do papel das profissões, das universidades e do Estado, que atuam de forma racional nos processos. $\mathrm{O}$ conceito de isomorfismo pode ser usado para explicar o processo de homogeneidade estudado por Dimaggio e Powell (1983). Para estes autores são identificados três mecanismos pelos quais a mudança isomórfica acontece: o coercitivo (via influência política e legitimidade), o mimético (pela incerteza) e o normativo (por padrões associados ao processo de profissionalização). O processo de objetificação, na visão desses autores, pode ser estudado à luz do isomorfismo. Importante observar-se que a existência de panaceias terá maior chance de ocorrer quanto maior for o mercado para tais inovações. (TOLBERT; ZUCKER, 1999)

Na visão de Tolbert e Zucker (1999), a institucionalização também é impactada pelo processo de difusão. Strang e Meyer (1993) definem a difusão como um processo racional de aprendizagem por meio da experiência dos outros, em que os meios e os fins não são facilmente identificáveis. Na visão deles, o processo de difusão se dá pela interação dos atores e da construção conjunta de alguma prática. Desta forma, para esses autores o apreço entre as partes está ligado ao mesmo tipo de categoria social, ou seja, imagens que evocam a amizade levarão a uma rápida difusão. (STRANG; MEYER, 1993)

Na visão de Strang e Meyer (1993), a homogeneização estudada por Dimaggio e Powell (1983) atua como um acelerador da difusão, que para Strang e Meyer (1993) também é acelerada e redirecionada pela teorização. Ainda para Strang e Meyer (1993), a teorização age com efeito de difusão mais rápido em modelos altamente abstratos e complexos, pois estes levam à formulação de modelos gerais, os quais dão significado e facilitam a comunicação e a adoção. Por fim, pode-se descrever a teorização como um fenômeno que contribui para a difusão.

Para Tolbert e Zucker (1999), a institucionalização se consolida no processo chamado de sedimentação. Este processo está associado ao estágio de total institucionalização. Para as autoras ele é obtido quando o uso da instituição se dá continuamente de forma estável por gerações sucessivas de atores. Para tanto, conhecer os fatores que afetam a difusão e a retenção da instituição no longo prazo, tais como grupos que se propõem a atuar e a legislar contra ou a favor, são pontos-chave para a sua sedimentação. Por outro lado, essas autoras, em conjunto com Covaleski e Dirsmith (1988) e Rowan (1982), argumentam que, algumas vezes, a ausência de oposição direta não significa ausência de obstáculos, pois a própria impossibilidade de associar resultados demonstráveis pelo uso de tais artefatos pode ser suficiente para afetar a sua difusão devido à redução dos esforços de seus defensores na continuidade de seus usos. Outro ponto a ser considerado é que, em situações nas quais os processos de teorização são mantidos de forma contínua, estabelece-se um ambiente favorável a inovações, o que possibilita que elementos concorrentes encontrem espaço para surgir e prosperar. (ABRAHAMSON, 1991)

Por fim, o processo reverso ao de institucionalização é chamado de desinstitucionalização. Sua ocorrência requer um novo e grande estímulo no ambiente (externo ou interno), de modo a oportunizar a ação de outros atores interessados em explorar as novas vantagens e desvantagens de novos artefatos, ou a fazer com que os atuais atores se desinteressem pelo uso do artefato atual. (TOLBERT; ZUCKER, 1999; LAWRENCE; WINN; JENNINGS, 2001) 
Salienta-se que a cada um dos processos identificados na Figura 1 (habitualização, objetificação e sedimentação) estão associadas forças específicas responsáveis pela ocorrência destes processos (causais e críticas para cada processo). Por meio desse conjunto de forças e processos descritos anteriormente é possível fazer uma associação deles com os estágios de institucionalização, a saber: a) mudanças tecnológicas, legislação, forças de mercado e processo de habitualização com o estágio de pré-institucionalização; b) monitoramento organizacional, teorização e processo de objetificação com o processo de semiinstitucionalização; e c) difusão, impactos positivos, resistências de grupos de interesse, defesa de grupos, heterogeneidade de usuários e processo de sedimentação com o estágio de total institucionalização.

Cabe, entretanto, uma reflexão sobre as motivações que fazem com que instituições sejam adotadas e mantidas. O estudo de Brizolla et al. (2015), que analisa a adoção de um BSC em uma instituição de ensino no sul do Brasil, constatou que as questões técnicas e racionais foram igualmente relevantes para a dimensão simbólica que acaba sendo refletida pelo grupo à medida que partilham princípios institucionais. Dentro desta ótica das motivações pode-se considerar a legitimidade como um forte motivo, que também dá sentido social a ações relevantes, tais como as ligadas à sustentabilidade sob a ótica das dimensões econômica, social e ambiental. (CASAGRANDE; LAVARDA, 2015)

Em cenários de incerteza, seguir ações que são realizadas por empresas líderes e bemsucedidas em seus mercados pode parecer socialmente acertado. Ações miméticas são percebidas nas organizações e contribuem para a formação de setores. Eberle e Colauto (2014) identificaram, em uma empresa do setor elétrico, a pressão mimética como forte motivadora para a adoção de um BSC, que surge em contextos altamente institucionalizados e de grande incerteza.

Thornton, Jones e Kury (2005) acreditam que as lógicas institucionais fornecem a teoria para se entender como o conteúdo da cultura influencia a mudança organizacional, enquanto o sequenciamento de evento histórico revela os padrões subjacentes de transformação cultural. Também são percebidas as diversas racionalidades dos atores organizacionais que agem no sentido de restringir as ações da empresa no processo de aceitação da mudança ou, ao contrário, que levam à aceitação desta. (GUERREIRO; RODRIGUES; CRAIG, 2012) Lounsbury e Boxenbaum (2013), refletindo sobre a obra de Friedland e Alford (1991, trazem à tona uma abordagem de lógicas institucionais que fornece uma "concepção não funcionalista da sociedade, sendo visto como um sistema potencialmente contraditório interinstitucional”. (FRIEDLAND; ALFORD, 1991, p. 240). Neste enfoque são apresentados três níveis de análise: negociação e competição individual, organizações em conflito e coordenação, e instituições em contradição e interdependência. No centro do imaginário está delineada a noção de contradição institucional e o fato de que as lógicas institucionais devem ser entendidas como, simultaneamente, materiais e simbólicas. Smets e Jarzabkowski (2013) desenvolveram um modelo relacional entre complexidade institucional e trabalho que dá suporte para reflexões sobre temas atuais a respeito de complexidade institucional e trabalho institucional de três maneiras: a) a perspectiva institucional se apresenta dentro de uma perspectiva relacional e, desta forma, as lógicas e suas contradições são usadas para explicar o contexto institucional em vez de dados; b) como a complexidade institucional tem interação dinâmica com a ação, vista como resultado da intencionalidade e do esforço; e c) o papel do trabalho diário (práxis) das pessoas que lidam com as

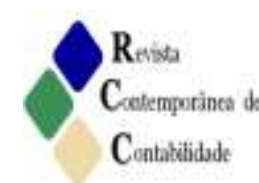


complexidades institucionais em seu dia-a-dia como meio de interação e ação dos indivíduos que fazem parte de seus contextos.

Wrubel, Toigo e Lavarda (2014) analisaram o processo de institucionalização das rotinas contábeis, por meio dos conceitos de Tolbert e Zucker (1999) e Seo e Creed (2002), no setor de serviços contábeis por meio da resposta de 43 profissionais que atuavam em escritórios de contabilidade. Os resultados mostraram que este processo é afetado por 5 (cinco) fatores de mudanças institucionais e 8 (oito) fatores de contradições institucionais e práticas humanas. Popik e Lavarda (2015) realizaram um estudo em uma cooperativa do Estado de Santa Catarina que mostrou que as contradições institucionais e a práxis impulsionaram a implantação e a institucionalização do planejamento estratégico. Este estudo permitiu que os pesquisadores verificassem que a ineficiência dos controles pré-existentes e o desalinhamento de interesse entre os gerentes foram as contradições institucionais que estimularam a ação humana. Por meio dela, a práxis foi a materializadora da mudança. Os principais agentes de mudança identificados foram os diretores, os gerentes e o consultor. Soeiro, Miranda e Araújo (2016) investigam as contradições institucionais, conforme o entendimento de Seo e Creed (2002), que podem ser usadas para explicar a decisão de mudança da alta administração de uma empresa nordestina de alta tecnologia, mais especificamente, para a contratação de um CEO (Chief Executive Officer). Foram identificadas três fontes de contradições institucionais que motivaram a mudança: a ineficiência técnica, a não adaptabilidade e a conformidade institucional.

Svenningsen, Boxenbaum e Ravasi (2016) estudam como os funcionários lidam com a complexidade institucional em um ambiente organizacional. O cenário empírico é uma empresa francesa de energia (atua na geração de energia elétrica por meio de placas fotoelétricas) que desenvolve simultaneamente uma lógica de ciência e uma lógica de mercado através de várias parcerias de pesquisa com agentes públicos e privados envolvidos na captura e transmissão de energia. Os autores se valeram da literatura sobre lógicas institucionais e organizações híbridas (definidas como organizações que incorporam elementos de diferentes lógicas). Foi observada a existência de duas lógicas institucionais que parecem caracterizar o ambiente organizacional, incluindo suas múltiplas parcerias. Por um lado, os indivíduos percebem a existência de uma lógica científica associada à liberdade, um horizonte de tempo mais longo, e a busca de publicações de baixo custo e com foco em exploração da pesquisa. Por outro lado, os indivíduos percebem uma lógica de mercado caracterizada por menos liberdade, um horizonte de tempo mais curto e a busca de patentes através da produção e do desenvolvimento de determinados tipos de pesquisa. A pesquisa demonstrou que os indivíduos expostos à mesma complexidade institucional usam diferentes estratégias para lidar com ela e para identificar algumas das características cognitivo-afetivas que explicam as suas preferências por uma determinada estratégia.

Wanderley e Soeiro (2016) examinam um caso de insucesso na implantação de um BSC em uma empresa de energia elétrica. Para Seo e Creed (2002) o processo de mudança é possível devido à acumulação de contradições institucionais - como a não adaptabilidade e as lacunas de eficiência - que permite que a práxis humana introduza a mudança. $\mathrm{O}$ trabalho conclui que o insucesso na implantação do BSC foi devido à falta de contradições institucionais e à falta de ação da práxis humana como consequência, o que impediu que o BSC substituísse os sistemas de avaliação de desempenho pré-existentes. Esse trabalho contribui com a formulação de um modelo que avalia mudanças bem-sucedidas (as que de fato levam à mudança institucional) em comparação com as malsucedidas (as que levam ao abandono, ou 
ainda as que mantêm o uso somente por questões de legitimidade, mas sem a produção da mudança institucional).

Por fim, ainda nos aportes teóricos, Rodrigues (2016) investigou o estágio de institucionalização e legitimação na adoção e implantação de um Centro de Serviços Compartilhados (CSC) em um grupo de empresas de prestação de serviços de tecnologia. O constructo teórico para o processo de institucionalização teve como orientação as obras de Tolbert e Zucker (1999) e de Burns e Scapens (2000), e para os mecanismos de legitimação valeu-se do trabalho de Scott (2001). Informações obtidas por meio de entrevistas tiveram seu conteúdo analisado com base na comparação dos elementos obtidos empiricamente e sua comparação com a teoria permitiu inferir-se que o CSC estudado se encontrava na fase de objetificação (conforme TOLBERT; ZUCKER, 1999) e na de codificação (conforme BURNS; SCAPENS, 2000).

Entende-se que os elementos identificados nas pesquisas mais recentes citadas e analisadas anteriormente (quais sejam, lógicas e contradições institucionais, as racionalidades dos atores organizacionais com suas intencionalidades e esforços), todos vistos sob a ótica do sequenciamento do evento histórico e da ação da práxis humana, constituem os motivadores para que forças sejam geradas nas diversas dimensões do processo de institucionalização de artefatos da contabilidade gerencial.

\section{Metodologia da Pesquisa}

Para a apresentação da metodologia faz-se necessário o entendimento prévio sobre a empresa estudada e sua relevância econômico-social. Com o intuito de preservar a confidencialidade, o nome da empresa estudada será omitido, portanto passa a ser doravante denominada EAE, uma sigla para "empresa de águas e esgoto". A EAE é uma empresa de capital misto (público e privado). Sua área de atuação é a região sudeste do Brasil, onde ela atende a uma grande população (milhões de habitantes) com serviços de tratamento de água, coleta e tratamento de esgotos. A EAE pode ser considerada de grande porte, seja pelo total de ativos, pelo patrimônio líquido ou mesmo pelo número de funcionários. Sua estrutura é composta de diretorias operacionais, corporativas e unidades de negócio que operam de forma descentralizada e com baixa integração entre as partes.

A EAE sofreu um processo de transformação em sua gestão, o qual ocorreu acentuadamente na primeira década dos anos 2000, inicialmente por meio de iniciativas que surgiram de grupos de colaboradores dentro das diretorias. A princípio, esse processo não pode ser considerado como corporativo; entretanto, a partir de 2004, a gestão corporativa começou a coordenar e a integrar as iniciativas das diretorias, promovendo a utilização de um processo de gestão integrado (PGI). O PGI utilizado pela EAE pode ser considerado um artefato de contabilidade gerencial caracterizado pela integração de práticas e modelos que envolvem prática de planejamento contínuo, a qual atende às dimensões estratégicas e operacionais e que se vale de metodologias e práticas associadas ao planejamento estratégico, planejamento operacional, orçamento empresarial, GBV, BSC e gestão de projetos.

Esse processo foi desenvolvido pelo grupo gestor da EAE com o suporte de uma empresa de consultoria governamental, sendo que a modelagem decorrente proposta consolidava o uso integrado de diversas práticas de gestão com o intuito de contribuir para o

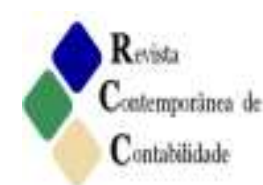


cumprimento da missão da empresa e maximizar o seu valor econômico. O PGI da EAE estava em processo de implantação desde 2004; entretanto, devido às grandes dimensões da organização (porte, número de colaboradores e cobertura geográfica) e à complexidade do modelo, sua implantação demandou vários anos. O PGI, durante o período de sua utilização 2004 a 2010 -, de acordo com os relatórios de desempenho da EAE, efetivamente contribuiu com o processo de gestão, integrando decisões e ações relacionadas com projetos de alto impacto e complexidade para a continuidade da companhia (e da sociedade).

Dentre as temáticas conflitantes que eram debatidas nos processos de decisão que se valiam do PGI estavam questões relacionadas aos diferentes papéis atribuídos à EAE por seus atores organizacionais. Alguns deles entendiam que a EAE tinha um papel prioritariamente social e que os resultados econômicos não eram relevantes. Na EAE eles eram chamados internamente de "sanitaristas". Por outro lado, como uma empresa mista, alguns entendiam que a empresa deveria gerar resultados econômico-financeiros, e que sem eles nada poderia ser conseguido. Estes eram chamados internamente de "financistas". Desses dois grupos de colaboradores emergiam tensões que influenciavam os planejamentos e as percepções de importância que se dava ao uso de práticas de gestão.

Outro aspecto importante a ser considerado é que a EAE, como empresa de capital misto, sofria influência política na definição de alguns cargos. No final da primeira década dos anos 2000, em decorrência de mudanças políticas, houve também a mudança do presidente e de alguns executivos do quadro da companhia. O novo presidente iniciou um processo de mudança das práticas de gestão, desconsiderando o processo estruturado préexistente (PGI).

O levantamento de dados para esta pesquisa deu-se no ano de 2010, ocasião em que parte significativa do processo integrado de gestão estava deixando de ser utilizado em virtude da indisponibilidade de agenda do presidente e de diretores para os ritos associados ao PGI, assim como de sua decisão em focar os esforços de gestão com base na metodologia de GBV dentro de um contexto de concorrência com o PGI, anulando um dos pilares do modelo que era o da integração entre artefatos da contabilidade gerencial.

Dado o contexto apresentado, entende-se que embora os dados utilizados nesta pesquisa sejam do ano de 2010, as temáticas apresentadas são atemporais e altamente relevantes para que se possa analisar o contexto do surgimento de tensões, de diferentes racionalidades, diferentes visões sobre o papel da organização e, em consequência deste contexto, das forças que causam mudanças nas instituições e que as levam a processos de institucionalização e/ou desinstitucionalização.

Metodologicamente, a pesquisa pode ser considerada como descritiva e qualitativa. Inicialmente foi desenvolvida uma pesquisa bibliográfica para identificar os elementos teóricos que podem explicar o problema. (CERVO; BREVIAN, 2002, p.65) A entrevista semiestruturada também foi utilizada como técnica de coleta de dados, com o propósito de se obter informações relevantes e detalhadas a respeito do objeto de estudo, gerando uma base de dados primários.

Jones e Raey (2015) identificam três diferentes técnicas, mas não exclusivas, que foram usadas por pesquisadores de 1991 a 2014, de modo a convencerem seus leitores de que eles estão realmente estudando lógicas institucionais. São elas: padrão de dedução, padrão de correspondência e padrão de indução. Algumas características apresentadas pelos autores estão resumidas na Tabela 1. 
Evidências das forças causais críticas dos processos de institucionalização e desinstitucionalização em artefatos da contabilidade gerencial.

\begin{tabular}{|c|c|c|c|}
\hline \multicolumn{4}{|c|}{ TABELA 1 - Abordagens qualitativas capturam lógicas institucionais } \\
\hline & Padrão de dedução & $\begin{array}{c}\text { Padrão de } \\
\text { correspondência }\end{array}$ & Padrão de indução \\
\hline Descrição & $\begin{array}{l}\text { Reúne grande volume de dados } \\
\text { (principalmente textos), converte } \\
\text { textos em ocorrências contábeis e } \\
\text { usa métodos analíticos para } \\
\text { revelar padrões. Privilegia } \\
\text { técnicas analíticas. }\end{array}$ & $\begin{array}{l}\text { Identifica padrões (tipo } \\
\text { ideal de lógicas) da } \\
\text { literatura existente e, } \\
\text { em seguida, compara os } \\
\text { dados com o tipo ideal. } \\
\text { Privilegia a teoria e a } \\
\text { pesquisa existentes. }\end{array}$ & $\begin{array}{l}\text { Concentra-se em dados brutos } \\
\text { usando o processo de baixo } \\
\text { para cima de modo a } \\
\text { identificar padrões (lógicas) } \\
\text { que podem então ser } \\
\text { comparadas com a literatura } \\
\text { existente. Privilegia o } \\
\text { pesquisador. }\end{array}$ \\
\hline Ontologia & $\begin{array}{l}\text { O mundo social é construído e } \\
\text { historicamente incorporado. Estas } \\
\text { construções empiricamente } \\
\text { existem e criam consequências, } \\
\text { que podem ser apontadas e } \\
\text { contadas. }\end{array}$ & $\begin{array}{l}\text { O mundo social é } \\
\text { construído e a } \\
\text { compreensão ocorre } \\
\text { com a interação entre as } \\
\text { teorias e dados } \\
\text { empíricos anteriores } \\
\text { com os achados atuais. }\end{array}$ & $\begin{array}{l}\text { O mundo social é construído e } \\
\text { a linguagem traz fatos na } \\
\text { consciência. Ela desempenha } \\
\text { um papel constitutivo. }\end{array}$ \\
\hline Epistemologia & Estruturalista semiótica. & Empirismo analítico. & Interpretativismo. \\
\hline Benefícios & $\begin{array}{l}\text { Capta mudanças históricas e } \\
\text { padrões ao longo do tempo. } \\
\text { Permite a redução de dados, a } \\
\text { representação e a visualização. } \\
\text { Facilita a análise de grande } \\
\text { volume de dados. Os achados são } \\
\text { vistos como mais generalizáveis. }\end{array}$ & $\begin{array}{l}\text { Captura categorias } \\
\text { essenciais para } \\
\text { comparação. Facilita a } \\
\text { análise consistente em } \\
\text { lógicas. Facilita a } \\
\text { comparação com outros } \\
\text { estudos. }\end{array}$ & $\begin{array}{l}\text { Capta nuances de práticas } \\
\text { localizadas. Apresentação de } \\
\text { dados retém contexto rico. } \\
\text { Captura explicações de } \\
\text { valores e crenças dos atores. } \\
\text { Facilita o desenvolvimento da } \\
\text { teoria. }\end{array}$ \\
\hline
\end{tabular}

Fonte: Jones e Raey (2015, p.3)

Nesta pesquisa os padrões utilizados foram os de correspondência e de indução. Espera-se identificar padrões que tenham correspondência com a teoria, mas que ampliem o entendimento teórico sobre um determinado fato e, também por meio de dados brutos (textos advindos das entrevistas), identificar padrões (lógicas) que possam então ser comparados com a literatura existente. A revisão teórica e o mundo social construído por meio da linguagem suportam a perspectiva ontológica. Os dados obtidos foram analisados à luz da teoria e com isto foram capturadas novas categorias sobre o tema em estudo, as quais contribuem para o desenvolvimento da teoria.

Para melhor orientação da elaboração do roteiro de entrevista, além das referências bibliográficas também foram coletados dados secundários advindos de 303 (trezentos e três) documentos fornecidos pela EAE, os quais foram produzidos por ela durante o processo de implantação do PGI. Os documentos eram de diversas naturezas: seminários, folhas de processos de trabalho, planos de ação, diagramas, agendas internas de atividades, manuais, $e$ mails, propostas de consultorias e discursos. Com esse material foi possível conhecer a estrutura do PGI da EAE e os esforços que foram realizados para a sua implantação e uso.

Foram realizadas 4 (quatro) entrevistas com gestores de carreira da organização, sendo um de cada diretoria. Cada um deles estava na organização há mais de 15 (quinze) anos em carreira gerencial. Acrescente-se também que cada um deles foi o responsável, em sua diretoria, pelo processo de implantação do PGI e permanecia à sua frente, respondendo pelas ações de manutenção de seu uso na ocasião das entrevistas. Pode-se considerar que sua experiência e ação, como um todo, representam o conjunto de conhecimento sobre o 
enfrentamento das adversidades que aconteceram no processo de implantação e uso do PGI na EAE. O roteiro abordou questões relativas ao PGI, classificadas por meio das forças causais dos processos de institucionalização/destinstitucionalização descritos por Tolbert e Zucker (1999).

As entrevistas foram gravadas e tiveram duração de $1 \mathrm{~h}$ a $1,5 \mathrm{~h}$ cada. Ao término das gravações, cada uma delas foi transcrita na íntegra e as transcrições foram encaminhadas para os respondentes para autorização de seu uso. Acrescente-se que as entrevistas foram realizadas entre outubro e novembro de 2010 na sede da organização objeto do estudo. Após a confirmação dos entrevistados quanto à integridade do seu conteúdo, este foi analisado.

Para Bardin (2009, p. 44), da análise de conteúdo se inferem conhecimentos relativos às condições de produção e recepção das mensagens, explicitando e sistematizando o conteúdo delas. A reunião de dados por meio de um sistema de categorias permite o entendimento de um conjunto de informações que estavam presentes, porém não acessíveis se não analisadas por meio de tal recurso. (BARDIN, 2009, p. 57) A fonte de informação pode ser um texto escrito em um livro, documentos gerados em um escritório ou obtidos por meio da transcrição de entrevistas. Para Bardin (2009, p. 90), o grande paradoxo a ser ultrapassado no uso de materiais obtidos em entrevistas é o fato de que o pesquisador, na tentativa de inferir algo representativo para um grupo, faz uso das palavras do entrevistado dentro de sua singularidade individual. O processo de análise de conteúdo observou as proposições metodológicas de Bardin (2009), atendendo às etapas de pré-análise, codificação, categorização e inferência.

A fase de pré-análise foi composta pelos procedimentos de revisão teórica, leitura preliminar das transcrições das entrevistas, formulação de variáveis investigativas que foram associadas às bases teóricas, suas possíveis motivações e formas pelas quais são observadas no dia-a-dia da organização estudada, trazendo, por fim, o elemento da Teoria Institucional correlato, o qual permite expandir o entendimento da abrangência e o alcance das forças causais críticas inerentes ao processo de institucionalização. A Tabela 2, abaixo, foi construída como resultado dessa fase.

TABELA 2: Constructo decorrente da etapa de pré-análise de Bardin (2009)

\begin{tabular}{|c|c|c|c|}
\hline Categorias & $\begin{array}{c}\text { Estágios de } \\
\text { Institucionalização } \\
\text { Equivalentes }\end{array}$ & $\begin{array}{l}\text { Identificação das causas e } \\
\text { motivações }\end{array}$ & Teoria Institucional \\
\hline $\begin{array}{l}\text { Mudanças } \\
\text { Tecnológicas; } \\
\text { Legislação; Forças de } \\
\text { Mercado e Processo de } \\
\text { Habitualização. }\end{array}$ & Pré-institucional. & $\begin{array}{l}\text { Estímulos que causam a } \\
\text { necessidade da mudança } \\
\text { ou o rearranjo das } \\
\text { práticas. }\end{array}$ & $\begin{array}{l}\text { Covaleski e Dirsmith (1988); } \\
\text { Dimaggio e Powelll (1983); } \\
\text { Meyer e Rowan (1977); Scott } \\
\text { (2001); Tolbert e Zucker (1999). }\end{array}$ \\
\hline $\begin{array}{l}\text { Monitoramento, } \\
\text { atividade de teorização } \\
\text { e processo de } \\
\text { objetivação. }\end{array}$ & Semi-institucional. & $\begin{array}{l}\text { Mecanismos de } \\
\text { monitoramento em busca } \\
\text { de instituições } \\
\text { alternativas; construção } \\
\text { dos arranjos estruturais } \\
\text { que atendem as } \\
\text { necessidades das } \\
\text { organizações e atores. }\end{array}$ & $\begin{array}{l}\text { Dimaggio e Powelll (1983); } \\
\text { Meyer e Rowan (1977); Tolbert } \\
\text { e Zucker (1999). }\end{array}$ \\
\hline
\end{tabular}


Evidências das forças causais críticas dos processos de institucionalização e desinstitucionalização em artefatos da contabilidade gerencial.

\begin{tabular}{|c|c|c|c|}
\hline Categorias & $\begin{array}{c}\text { Estágios de } \\
\text { Institucionalização } \\
\text { Equivalentes }\end{array}$ & $\begin{array}{c}\text { Identificação das causas e } \\
\text { motivações }\end{array}$ & Teoria Institucional \\
\hline $\begin{array}{l}\text { Impactos positivos, } \\
\text { resistências de grupos, } \\
\text { defesas de grupos, } \\
\text { difusão, legitimidade, } \\
\text { poder, } \\
\text { heterogeneidade de } \\
\text { usuários, processo de } \\
\text { sedimentação. }\end{array}$ & $\begin{array}{l}\text { Total } \\
\text { institucionalização. }\end{array}$ & $\begin{array}{l}\text { As lideranças e o poder; } \\
\text { legitimidade e } \\
\text { legitimação; grupos e } \\
\text { interesses. }\end{array}$ & $\begin{array}{l}\text { Dimaggio e Powelll (1983); } \\
\text { Meyer e Rowan (1977); Tolbert } \\
\text { e Zucker (1999). }\end{array}$ \\
\hline $\begin{array}{l}\text { Surgimento de } \\
\text { instituições } \\
\text { competidoras. }\end{array}$ & Desinstitucionalização. & $\begin{array}{l}\text { Dissociação de benefícios } \\
\text { do uso do artefato. }\end{array}$ & $\begin{array}{c}\text { Abrahamson (1991); Lawrence, } \\
\text { Winn e Jennings (2001); Tolbert } \\
\text { e Zucker (1999). }\end{array}$ \\
\hline
\end{tabular}

Fonte: os autores

Para a fase de codificação buscou-se uma leitura das transcrições das entrevistas de modo a se identificar, por trás do discurso dos respondentes, elementos que caracterizassem forças capazes de atuar no sentido de institucionalizar ou desinstitucionalizar o PGI e/ou as práticas de gestão a ele associadas. Nesta fase utilizou-se a prática da análise de discurso (AD) de forma estrutural textual. (GODOI, 2010) O processo de AD está associado à busca de sentido que se dá pela interpretação de textos (orais ou escritos), imagens ou linguagem corporal. A estrutura conceitual que sustenta a $\mathrm{AD}$ pode ser identificada pela seguinte formulação: $\mathrm{AD}=$ ideologia + história + linguagem. A ideologia trata do posicionamento do sujeito quando de sua filiação a um discurso com base em sistema de ideias que constituem essa representação; a história representa o seu contexto histórico-social, enquanto a linguagem é quem gera as "pistas" (materialidades) referentes aos sentidos que o sujeito pretende dar à ideologia no contexto histórico em que as práticas estão inseridas. (CAREGNATO; MUTTI, 2006).

Cada novo tipo de força identificada era associado a elementos correlatos da Teoria Institucional, a fim de obter-se um significado para cada achado. Desta forma, com base nas observações dessas novas forças, foram definidas as regras de recorte do texto. Para tanto, nos textos transcritos das entrevistas, cada parágrafo foi analisado na tentativa de se identificar causas e motivos que pudessem revelar algum elemento correlato da Teoria Institucional que atua como uma força causal crítica para o processo de institucionalização/desinstitucionalização. (ABRAHAMSON, 1991; COVALESKI; DIRSMITH, 1988; DIMAGGIO; LAWRENCE; WINN; JENNINGS, 2001; POWELLL, 1983; MEYER; ROWAN, 1977; SCOTT, 2001; TOLBERT; ZUCKER, 1999).

Cada um dos novos elementos identificados foi introduzido em uma nova tabela (Tabela 3), que apresentou a frequência com que esse elemento foi citado e por qual dos entrevistados. O objetivo desta tabela foi o de estabelecer as categorias de forças identificadas pelos respondentes. Este processo se deu com vistas à identificação da saturação da amostragem. (FONTANELLA; RICAS; TURATO, 2008) Apesar do seu pequeno número, pode-se observar a repetição da evidenciação das forças pelos diferentes entrevistados. A maior frequência observada na percepção de alguns tipos de forças evidencia a saturação da amostragem quanto a determinadas forças. Algumas, entretanto, em função de sua baixa

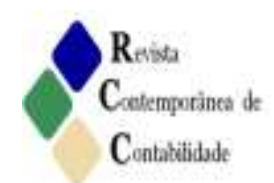


frequência, requereriam ainda um maior aprofundamento investigativo ou a oportunidade de se entrevistar outras pessoas que pudessem confirmar ou negar as evidências. Isto não ocorreu, porém, devido às limitações relacionadas à disponibilidade de agenda dos entrevistados. Salienta-se, entretanto, que se outros profissionais fossem entrevistados, estes seriam de outro nível funcional e as realidades nas quais estariam inseridos, diferenciadas do grupo de entrevistados, poderiam revelar outros tipos de percepções que não necessariamente contribuiriam para a afirmação ou a negação das forças percebidas.

Por fim, extraem-se as forças identificadas e verifica-se como elas, à luz da teoria e da prática, podem auxiliar na compreensão das consequências que elas representam para o processo de institucionalização/desinstitucionalização de artefatos de contabilidade gerencial, mais especificamente para o PGI da EAE.

\section{Análise dos Resultados}

Na década de 1990, a EAE passou por uma grave situação financeira, com risco de insolvência. Em meados daquela década a nova direção, que assumiu a empresa em decorrência de evento político, centralizou sua gestão na figura do orçamento de caixa com poderes para a área financeira, mas, por outro lado, considerando a amplitude geográfica de atuação da empresa, promoveu uma reestruturação de sua organização em unidades de negócio. Como consequência da falta de recursos financeiros e da descentralização houve uma redução na administração corporativa, em particular na função de planejamento. Outra característica da organização era a estabilidade dos funcionários, inclusive em cargos gerenciais, como por exemplo, gerentes e superintendentes atuando em cargos similares há mais de 15 (quinze) anos, e práticas de remuneração variável, não vinculada a critérios de meritocracia.

Esse contexto descrito está repleto de contradições institucionais, tais como: centralização do orçamento de caixa dando poder de gestão para a diretoria financeira, contrapondo o processo de reorganização em unidades de negócio (POPIK; LAVARDA, 2015; SOEIRO; MIRANDA; ARAÚJO, 2016); o próprio papel da organização, vista por alguns sob o enfoque social e por outros como uma empresa orientada para o mercado e para resultados econômico-financeiros; e a influência das novas tecnologias sobre os processos de gestão, que eram percebidas em organizações de mercado. (EBERLE; COLAUTO, 2014)

A busca pelo restabelecimento da administração corporativa começou quando houve a decisão de implantação do PGI em meados da primeira década dos anos 2000. As contradições lógicas e as pressões isomórficas (POPIK; LAVARDA, 2015; SOEIRO; MIRANDA; ARAÚJO, 2016; SMETS; JARZABKOWSKI, 2013; LOUNSBURY; BOXENBAUM, 2013) geraram a oportunidade para que forças causais, identificadas nesta pesquisa e apresentadas na Tabela 3, pudessem surgir e atuar no processo da criação de uma nova instituição. Nesse momento era notória a defasagem tecnológica da organização em termos de tecnologias de gestão e tecnologia da informação.

O projeto de implantação do PGI, com apoio de consultoria especializada, foi desenvolvido ao longo de 3 (três) anos. Por meio da práxis (POPIK; LAVARDA, 2015; WANDERLEY; SOEIRO, 2016; WRUBEL; TOIGO; LAVARDA, 2014) foram realizados os processos de implantação do PGI em toda a organização, tendo como âncora o modelo do 
BSC. Nesse período houve um ganho nas competências relacionadas à tecnologia de gestão, o que proporcionou o alinhamento entre a administração corporativa e as unidades de negócio.

Tal alinhamento i) permitiu a estruturação de projetos complexos que demandavam altos investimentos; ii) capacitou as principais lideranças, os gestores e técnicos de níveis operacionais; iii) fomentou um ambiente de busca de inovação; e, iv) integrou pessoas e processos. Contudo, o projeto ainda apresentava deficiências na estruturação de processos informatizados que dessem suporte às práticas e aos processos utilizados pelo PGI, dificuldades na projeção de resultados e metas financeiras por unidade de negócio, além da persistência de grupos de resistência com forte viés financeiro. Nessa ocasião, diversas questões e conflitos foram resolvidos, o que levou a uma redução das tensões em consequência do alinhamento das racionalidades (GUERREIRO; RODRIGUES; CRAIG, 2012) e da diminuição das contradições (POPIK; LAVARDA, 2015; SOEIRO; MIRANDA; ARAÚJO, 2016; SMETS; JARZABKOWSKI, 2013).

Esse estado institucional, aliado à manutenção de um ambiente favorável à inovação e à pressão de eventos políticos externos à empresa, proporcionou um ambiente desfavorável à estabilidade do PGI, dificultando a sua sedimentação (ABRAHAMSON, 1991; WANDERLEY; SOEIRO, 2016). Com a mudança na presidência em virtude de evento político começou o processo de desuso do PGI, cuja situação encontrada em 2010 refletia um processo de desinstitucionalização sustentada pela falta de agenda da alta administração, pela persistência das deficiências já mencionadas - que limitavam o uso do artefato - e pela decisão da diretoria de patrocinar outra solução para a gestão de desempenho, assim enfraquecendo o papel do planejamento na organização. Neste último contexto (quando da implantação do GBV), mais uma vez foram identificadas novas contradições e novas racionalidades que sustentam o processo de competição entre artefatos de contabilidade gerencial, assim enfraquecendo o artefato objeto de estudo. Cumpre salientar que o grupo de interesse favorável ao PGI tentou várias vezes retomar o uso e a difusão do artefato, mas sem sucesso, o que contribuiu para o aumento das tensões institucionais.

TABELA 3: Análise de frequência das forças causais identificadas

\begin{tabular}{|c|c|c|c|c|c|c|c|}
\hline \multirow{2}{*}{ Categorias } & \multirow{2}{*}{$\begin{array}{l}\text { Estágios de } \\
\text { Institucionali- } \\
\text { zação } \\
\text { Equivalentes }\end{array}$} & \multirow{2}{*}{$\begin{array}{l}\text { Elemento Correlato da Teoria Institucional } \\
\text { que atua como uma Força Causal Crítica }\end{array}$} & \multirow{2}{*}{$\begin{array}{l}\text { Fre- } \\
\text { quên- } \\
\text { cia }\end{array}$} & \multicolumn{4}{|c|}{ Entrevistados } \\
\hline & & & & $\mathbf{1}$ & 2 & 3 & 4 \\
\hline \multirow{4}{*}{$\begin{array}{l}\text { Mudanças } \\
\text { Tecnológicas; } \\
\text { Legislação e } \\
\text { Forças de } \\
\text { Mercado. }\end{array}$} & \multirow{4}{*}{$\begin{array}{l}\text { Pré- } \\
\text { institucional. }\end{array}$} & $\begin{array}{l}\text { Estrutura organizacional e conjunto de } \\
\text { instituições precedentes; }\end{array}$ & 1 & & & & 1 \\
\hline & & Monitoramento organizacional; & 3 & & & & 3 \\
\hline & & Busca de legitimidade e legitimação; & 4 & & & & 4 \\
\hline & & $\begin{array}{l}\text { Conformação de grupos a mandatos } \\
\text { institucionais. }\end{array}$ & 5 & 2 & & 1 & 2 \\
\hline \multirow{3}{*}{$\begin{array}{l}\text { Monitoramento, } \\
\text { teorização e } \\
\text { processo de } \\
\text { difusão. }\end{array}$} & \multirow{3}{*}{$\begin{array}{l}\text { Semi- } \\
\text { institucional. }\end{array}$} & Isomorfismo mimético; & 3 & 1 & 0 & & 2 \\
\hline & & Isomorfismo normativo; & 14 & 3 & 4 & 2 & 5 \\
\hline & & $\begin{array}{l}\text { Processo de teorização acerca de novas } \\
\text { instituições. }\end{array}$ & 22 & 7 & 2 & 5 & 8 \\
\hline
\end{tabular}




\begin{tabular}{|c|c|c|c|c|c|c|c|}
\hline \multirow{2}{*}{ Categorias } & \multirow{2}{*}{$\begin{array}{l}\text { Estágios de } \\
\text { Institucionali- } \\
\text { zação } \\
\text { Equivalentes }\end{array}$} & \multirow{2}{*}{$\begin{array}{l}\text { Elemento Correlato da Teoria Institucional } \\
\text { que atua como uma Força Causal Crítica }\end{array}$} & \multirow{2}{*}{$\begin{array}{l}\text { Fre- } \\
\text { quên- } \\
\text { cia }\end{array}$} & \multicolumn{4}{|c|}{ Entrevistados } \\
\hline & & & & 1 & 2 & 3 & 4 \\
\hline \multirow{12}{*}{$\begin{array}{l}\text { Impactos } \\
\text { positivos, } \\
\text { resistências de } \\
\text { grupos, defesas } \\
\text { de grupos. }\end{array}$} & \multirow{12}{*}{$\begin{array}{l}\text { Total institu- } \\
\text { cionalização. }\end{array}$} & Processo de difusão; & 17 & 5 & 4 & 4 & 4 \\
\hline & & Homogeneidade / Heterogeneidade dos atores; & 3 & & 1 & 1 & 1 \\
\hline & & $\begin{array}{l}\text { Existência de grupos de apoio ou de } \\
\text { resistência ao processo de sedimentação; }\end{array}$ & 10 & 3 & 2 & 1 & 4 \\
\hline & & $\begin{array}{l}\text { Associação do artefato com restrição de } \\
\text { recursos, associados ao poder e autointeresse; }\end{array}$ & 4 & & & 3 & 1 \\
\hline & & $\begin{array}{l}\text { Arranjo dos artefatos com base no } \\
\text { posicionamento e concordância das lideranças; }\end{array}$ & 8 & 3 & 3 & 1 & 1 \\
\hline & & Competição entre grupos; & 4 & 2 & 1 & 1 & \\
\hline & & Coerção pelo controle dos recursos; & 4 & & 2 & 1 & 1 \\
\hline & & $\begin{array}{l}\text { Redefinição dos contextos organizacionais em } \\
\text { função do ingresso de novos artefatos; }\end{array}$ & 4 & 3 & & 0 & 1 \\
\hline & & $\begin{array}{l}\text { Busca de legitimidade, mesmo que sem a } \\
\text { associação direta de benefícios obtidos pelo } \\
\text { uso da instituição; }\end{array}$ & 2 & & & & 2 \\
\hline & & $\begin{array}{l}\text { Papel normativo das instituições sobre os } \\
\text { atores em função do autointeresse; }\end{array}$ & 2 & & 1 & 1 & 0 \\
\hline & & Baixa variância na implementação; & 5 & 4 & & & 1 \\
\hline & & $\begin{array}{l}\text { Arranjo estrutural complexo, facilitando a } \\
\text { sedimentação. }\end{array}$ & 4 & 2 & 1 & 1 & \\
\hline \multirow{5}{*}{$\begin{array}{l}\text { Surgimento de } \\
\text { instituições } \\
\text { competidoras. }\end{array}$} & \multirow{5}{*}{$\begin{array}{l}\text { Desinstituciona- } \\
\text { lização. }\end{array}$} & $\begin{array}{l}\text { Dificuldade em associar benefícios com o uso } \\
\text { da nova instituição; }\end{array}$ & 6 & & & 1 & 5 \\
\hline & & $\begin{array}{l}\text { Processo longo de teorização predispondo a } \\
\text { organização a desenvolver instituições } \\
\text { concorrentes; }\end{array}$ & 3 & 1 & & & 2 \\
\hline & & Perda de patrocínio da alta direção; & 4 & 1 & 1 & 2 & \\
\hline & & Alta taxa de fracasso estrutural; & 3 & 2 & & 1 & \\
\hline & & $\begin{array}{l}\text { Ações que levam à descontinuidade do uso - } \\
\text { Desintitucionalização. }\end{array}$ & 4 & 1 & 1 & 2 & 0 \\
\hline
\end{tabular}

\section{Fonte: Os autores}

Com base na avaliação da saturação foram selecionados os elementos percebidos simultaneamente pelo maior número de entrevistados (três e quatro respondentes) para sua evidenciação neste trabalho, bem como para que se procedesse à análise de discurso articulada com a análise de conteúdo e a fundamentação teórica, todos apresentados a seguir. Para caracterizar cada elemento são apresentados trechos das transcrições das entrevistas seguidos de análises que buscam evidenciar os contextos institucionais que possibilitam o 
surgimento de forças que atuam no sentido de institucionalizar/ desintitucionalizar o PGI e os artefatos a ele associados.

\subsection{Força causal "conformação de grupos a mandatos institucionais"}

São apresentados os recortes das transcrições cuja análise levou à sua classificação no grupo do elemento "conformação de grupos a mandatos institucionais":

- Entrevistado 1: ... Porque aqui a gente fazia um horizonte de cinco anos, mas o quinto ano era praticamente descartado porque o horizonte era o período de governo, e isso é muito prejudicial, ...

- Entrevistado 3: ... Porque a empresa é uma empresa estatal, em que a cada quatro anos você sofre uma intervenção, que o governo do estado é o majoritário, e ele define normalmente a presidência e seus diretores.

- Entrevistado 4 :... Mas é fato também que quando você tem uma empresa que tem um ciclo de quatro em quatro anos, e você não sabe como vão ser os outros quatro, $[\ldots]$ e muitas vezes também você não consegue captar essa modelagem, esse modelo de gestão vem com alguma proposta de acompanhamento diferente. $[\ldots]$.

Pode-se observar, nos trechos de discursos, a influência do prazo do mandato da diretoria - por ser uma empresa estatal - tanto no processo decisório em si quanto no modelo de gestão. Tal fenômeno, que foi identificado por Covaleski e Dirsmith (1988), mostra que as organizações e os atores precisam se conformar aos mandatos institucionais, cuja consequência pode impactar o uso e os artefatos gerenciais. O contexto descrito revela a existência de conflitos institucionais decorrentes da convivência com diferentes lógicas que geram a instabilidade advinda de novos mandatos nas instituições existentes, assim oportunizando o surgimento de inovações mas com alto risco de fracasso de implantação.(POPIK; LAVARDA, 2015; SOEIRO; MIRANDA; ARAÚJO, 2016) No contexto da presente pesquisa, pode-se considerar que, em decorrência da existência de mandatos sucessivos, com troca de gestores a cada período de quatro anos, cria-se um ambiente onde as contradições institucionais perdem forças ao longo do mandato, e que levam ao fortalecimento das resistências à mudança. (WANDERLEY; SOEIRO, 2016)

\subsection{Força causal "isomorfismo normativo"}

São apresentados os recortes das transcrições cuja análise levou à sua classificação no grupo do elemento "isomorfismo normativo":

- Entrevistado 1: A gente chamou a consultoria para ajudar a elaborar a metodologia, e para nos ensinar a fazer o PGI.

- Entrevistado 2: Vários cursos foram dados para os gestores, engenheiros e analistas. Várias pessoas fizeram cursos na Universidade Corporativa [...] foi contratada a consultoria.

- Entrevistado 3: Nós construímos toda a metodologia do PGI. Então nós contratamos o pessoal da consultoria para eles desenvolverem a metodologia de implantação dentro da especificidade da empresa.

- Entrevistado 4: E aí foi que a gente adotou esse modelo de PGI, na época contratamos uma consultoria para dar um auxílio, mas era mais na construção, era para ter alguém de fora contribuindo. 
Pode-se observar, nos trechos de discursos, a influência do isomorfismo normativo no processo de implantação do PGI e das práticas a ele associadas. Dimaggio e Powell (1983) salientam o papel das universidades, consultorias e profissões como principais mecanismos desse tipo de isomorfia. Na organização em pauta, pode-se observar que o principal mecanismo foi a utilização de consultorias. A influência que estas consultorias exercem sobre os ambientes organizacionais pode ser considerada como uma força que age no sentido de institucionalizar novos artefatos. Elas atuam no processo de institucionalização quando do momento da implantação e do acompanhamento do uso.

\subsection{Força causal "processo de teorização acerca de novas instituições"}

São apresentados os recortes das transcrições cuja análise levou à sua classificação no grupo do elemento "processo de teorização acerca de novas instituições":

- Entrevistado 1: Então lendo os diagnósticos de empresas americanas e brasileiras você vê que o principal problema do planejamento estratégico mesmo é a dificuldade de você implementar a estratégia, [...]E a gente então adotou o PGI para tentar não vincular, mas conciliar as ações de planejamento com as ações físicas da empresa principalmente com o orçamento...

- Entrevistado 2: Você estar aplicando uma nova metodologia [...]você começa a exercitar e a trazer exemplos práticos de uma outra unidade que aplicou e você vê o resultado e aí o pessoal absorve.

- Entrevistado 3: Eu acho que ela (a atividade de teorização) é baixa. [...]. Na fase de implantação e na fase de desenvolvimento ela era muito alta, as pessoas davam muita importância. [...] o PGI foi construído pra empresa, de algum modo ele foi customizado...

- Entrevistado 4: E a base dele eram os conceitos da literatura. Não fugiu deles. Mas é lógico que a gente tentou adaptá-lo à nossa situação...

Pode-se observar, nos trechos de discursos, a influência da teorização como um mecanismo de construção de uma instituição que atenda simultaneamente às questões associadas à resolução do problema identificado, com base em lógicas suportadas pelas teorias.(TOLBERT; ZUCKER, 1999) Esse processo é entendido como uma prática social (práxis) à medida que existe a construção de um objeto por meio da ação humana coletiva.(POPIK; LAVARDA, 2015; STRANG; MEYER, 1993) Verifica-se claramente nos trechos a amplitude do problema organizacional a ser resolvido pelo PGI, envolvendo desde a gestão da estratégia até a gestão das operações em nível hierárquico das unidades de negócio. Como consequência, verifica-se também que a teorização ocorreu de forma muito intensa na fase de objetificação, que aconteceu dentro de um mesmo mandato.

\subsection{Força causal "processo de difusão"}

São apresentados os recortes das transcrições cuja análise levou à sua classificação no grupo do elemento "processo de difusão":

- Entrevistado 1: Eu diria que de 2004 a 2007 isso foi bastante intenso, foi o período que a gente mais viajou explicando a metodologia e acompanhando os seminários de planejamento e disponibilizando ferramentas..

- Entrevistado 2: Todo o material que nós tínhamos em meio magnético sempre foi passado para todos eles. Todas as apresentações, com muito material para

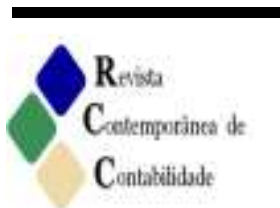


todos os gerentes e supervisores. Nós difundimos, não só presencial, mas também via magnética para todos...

- Entrevistado 3: Então o treinamento profundo, o treinamento superficial, o treinamento de conhecimento, enfim, de modo que toda a população EAE tenha o conhecimento...

- Entrevistado 4: Como esse negócio começou de baixo para cima, cada unidade foi criando o seu. Muitas vezes uma unidade copiou da outra, outra passou o sistema que tinha criado com um controle de plano de ação interno...

Pode-se observar, nos trechos de discursos, a influência da difusão como um processo racional de aprendizagem por meio da experiência dos outros, pela interação e construção conjunta de uma nova prática, dentro de um contexto social.(STRANG; MEYER, 1993) Por meio dela são alinhadas as diversas racionalidades (GUERREIRO; RODRIGUES; CRAIG, 2012) que pressionam a redução das contradições institucionais.(GUERREIRO; RODRIGUES; CRAIG, 2012; POPIK; LAVARDA, 2015) Em um primeiro momento são observadas grandes contradições que oportunizam a inovação. Por outro lado, verificando-se que a difusão foi muito intensa de 2004 a 2007 e depois foi bastante reduzida, pode-se inferir que no início havia uma forte influência institucional que foi reduzida por força do período de mandato, assim contribuindo para o fracasso do PGI. (WANDERLEY; SOEIRO, 2016)

\subsection{Força causal "homogeneidade/heterogeneidade dos atores"}

São apresentados os recortes das transcrições cuja análise levou à sua classificação no grupo do elemento "homogeneidade/heterogeneidade dos atores":

- Entrevistado 2: Nos grupos, é interessante [...] colocar pessoas operacionais e pessoas com formação administrativa. Não é só o administrativo que vai ganhar [...] Então se a gente não tiver na formação do grupo pessoas que estão na boca da vala, do dia-a-dia, você acaba estabelecendo ações às vezes impossíveis de se concretizar...

- Entrevistado 3: É um grupo de execução em que você tem representantes de cada diretoria, e assim bem diverso frente à sua formação. Você tem engenheiros, economistas, administradores, contadores, e esse grupo se reúne toda semana [...] o pessoal procura diversificar quais são as áreas que podem estar ajudando para poder fazer a contribuição...

- Entrevistado 4: Se você for em cada uma das unidades de negócio você vai ver o PGI e o desdobramento das ações dentro da área dele. Agora, o nível de conhecimento vai ser maior ou menor de acordo com a função do colaborador...

Nos trechos de discursos acima, pode-se observar a influência da heterogeneidade dos atores e demais usuários do PGI, o que evidencia a eficiência dos processos de teorização e difusão e, desta forma, uma atuação social mais ampla que leva a instituição a ser amplamente aceita e praticada pelo grupo social (TOLBERT; ZUCKER, 1999; POPIK; LAVARDA, 2015).

\subsection{Força causal "existência de grupos de apoio ou de resistência ao processo de sedimentação"}

São apresentados os recortes das transcrições cuja análise levou à sua classificação no grupo do elemento "existência de grupos de apoio ou de resistência ao processo de 
sedimentação":

- Entrevistado 1: Se fosse para fazer um campeonato de futebol, você podia botar os financistas de um lado, os de processos do outro, o do pessoal do cliente do outro e o pessoal de aprendizado para cá...

- Entrevistado 2: A gente tinha problemas de resistência. [...]. Então o patrocínio do diretor é fundamental.

- Entrevistado 3: Então nós estávamos exatamente num processo há quatro anos atrás, onde a gente consolidou o planejamento da EAE, um plano macro estratégico, nós estávamos desdobrando o PGI com as comunidades. E aí tem um pouco de resistência dentro das diretorias [...], e um confronto entre o corporativo e a unidade de negócio.

- Entrevistado 4: O pessoal da unidade X tem a dificuldade de fazer esse negócio amadurecer, porque tem uma resistência, tem uma inércia aí.

A influência dos grupos de resistência ao processo de sedimentação do PGI pode ser observada nos trechos de discursos acima. $\mathrm{O}$ contexto organizacional evidencia a existência de grupos com diferentes lógicas institucionais, parte advinda de autointeresse de suas lideranças e parte de motivações de diferentes ideologias. (GUERREIRO; RODRIGUES; CRAIG, 2012; SVENNINGSEN; BOXENBAUM; RAVASI, 2016) Isto pode ser percebido quando o discurso evidencia a ocorrência de resistência dentro das diretorias e unidades de negócio, associada a temas (financistas/sanitaristas) que caracterizam uma organização híbrida.

\subsection{Força causal "arranjo dos artefatos com base no posicionamento e concordância das lideranças"}

São apresentados os recortes das transcrições cuja análise levou à sua classificação no grupo do elemento "arranjo dos artefatos com base no posicionamento e concordância das lideranças":

- Entrevistado 1: Existe um processo na empresa que é um processo de construção dos instrumentos de gestão que detém a parte que você planeja e a parte que você orça.

- Entrevistado 2: Inclusive agora estamos num estágio onde o pessoal da informática está desenvolvendo um sistema para acompanhamento da GBV. Quem está tocando é o grupo interno da diretoria financeira. Da mesma forma, o PGI somos nós os interlocutores da alta administração e com a diretoria e com as nossas unidades de negócio. Também todas elas participaram.

- Entrevistado 3: Então assim, a gente deu mais importância para a GBV do que para o planejamento como um todo. Então de certo modo nessa gestão, dos quatro anos a gente, o nosso planejamento estratégico pela modelagem do PGI ficou meio desativado.

- Entrevistado 4: O próximo passo nosso é fazer o vínculo da GBV com seus indicadores, mas também fazer um vínculo desses indicadores ao orçamento, e também, dependendo do que a liderança maior queira, buscar esse vínculo do orçamento ao BSC, que faz todo o sentido...

A influência das lideranças no arranjo dos artefatos pode ser observada nos trechos de discursos acima, evidenciando a fraca contradição em que lideranças do nível funcional, por seu autointeresse, patrocinam o PGI mesmo sem o apoio institucional da alta administração e aceitam a convivência com outros artefatos gerenciais patrocinados e gerenciados por outras

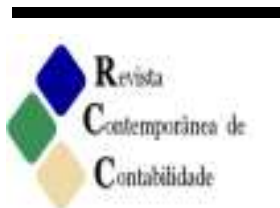


lideranças e áreas. A continuidade do uso não necessariamente representa a total institucionalização, mas sim, devido ao contexto institucional de baixas contrições, a observância de critérios de legitimidade (seja da prática ou dos agentes a ela associados). (WANDERLEY; SOEIRO, 2016)

\subsection{Força causal "competição entre grupos"}

São apresentados os recortes das transcrições cuja análise levou à sua classificação no grupo do elemento "competição entre grupos":

- Entrevistado 1: Os sanitaristas estão percebendo as necessidades dos financistas, da mesma forma os financistas estão também entendendo que tem uma parcela da população que independentemente ou não do poder de pagamento ela tem que ser atendida, ela tem que ter serviços de saneamento básico e esgotos, independentemente de poder pagar por isso ou não...

- Entrevistado 2: Nós não temos integração entre o orçamento e o planejamento, mas não só em função da ferramenta do PGI, isso vem de anos com várias ferramentas...

- Entrevistado 3: E aí a nova direção que veio entrou com mais uma ferramenta de suporte, que é a gestão de agregar valor para o acionista. [...]. Então assim, a gente deu mais importância para essa ferramenta específica do que para o planejamento como um todo. De certo modo, nessa gestão, dos quatro anos a gente, o nosso planejamento estratégico pela modelagem do PGI ficou parcialmente desativado...

Nos trechos de discursos acima, pode-se observar a influência da competição entre grupos, ainda no contexto dos grupos de resistência ao processo de sedimentação do PGI. Entretanto, aqui se evidenciam os efeitos das ações desses grupos, principalmente quanto à falta de integração entre planejamento e orçamento, que era um dos pilares do PGI, além da decisão da nova direção de implantar o GBV, assim gerando concorrência ao PGI e, consequentemente, o seu enfraquecimento pelo redirecionamento do patrocínio da diretoria ao outro artefato. $\mathrm{O}$ contexto organizacional evidencia que o uso dos artefatos pelos atores pode estar inserido nas situações em que o poder e o autointeresse, de dentro e de fora da organização, podem agir de forma determinante. (COVALESKI; DIRSMITH, 1988)

\subsection{Força causal "coerção pelo controle dos recursos"}

São apresentados os recortes das transcrições cuja análise levou à sua classificação no grupo do elemento "coerção pelo controle dos recursos":

- Entrevistado 2: Elaboramos todo o planejamento [...], mas nunca cabe no orçamento. Aí a gente faz o processo inverso: faz o planejamento em cima de um orçamento.

- Entrevistado 3: Então a EAE monta o orçamento, vê qual é a disponibilidade que a empresa tem para poder fazer, com base naquilo que ela vai arrecadar em relação à receita.

- Entrevistado 4: O grupo estratégico da UN priorizou as estratégias que entendeu que eram as mais importantes e em função das ações que foram previstas e dos recursos que a unidade de negócio tinha a gente foi priorizando [...] se [...] acabou o meu dinheiro então daqui para frente não se faz mais nada a não ser as ações que sejam feitas sem recursos financeiros.

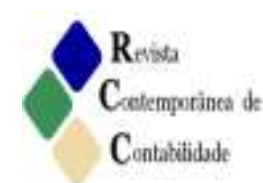


Pode ser observada, nos trechos de discursos, a influência da coerção pelo controle dos recursos como uma ação que reverte o processo lógico da construção do processo de planejamento, fazendo com que o ordenamento da decisão seja submisso à disponibilidade do recurso no orçamento. Covaleski e Dirsmith (1988) estudam os impactos que o controle de recursos representa sobre o sucesso da implantação do orçamento em universidades norteamericanas e conclui que o controle dos recursos atua de forma coercitiva sobre as decisões dos gestores. Ressalte-se ainda que tal problema é recorrente na organização objeto de estudo e já existia antes da implantação do PGI. Portanto, verifica-se o fracasso da tentativa de integrar o planejamento e o orçamento com a continuidade da situação original. Este contexto caracteriza novamente um conjunto de baixas contradições institucionais que impediram o sucesso do PGI. (WANDERLEY; SOEIRO, 2016)

\subsection{Força causal "arranjo estrutural complexo facilitando a sedimentação"}

São apresentados os recortes das transcrições cuja análise levou à sua classificação no grupo do elemento "arranjo estrutural complexo facilitando a sedimentação":

- Entrevistado 1: A gente trouxe a ferramenta de hierarquização de projetos. [...] a gente tem todo o conhecimento do PMI. O GBV foi trazido o ano passado para a EAE..

- Entrevistado 2: O GBV veio posteriormente à implantação do PGI. A gestão de projetos e a hierarquia de projetos foram elaboradas em paralelo ao BSC.

- Entrevistado 3: Têm $\mathrm{N}$ ferramentas de suporte à gestão[...] que a gente usa pelo nome de PGI...

Pode ser observada, nos trechos de discursos, a influência do arranjo estrutural complexo que facilita a sedimentação. (STRANG; MEYER, 1993) Nota-se no PGI que sua concepção alinhou diferentes artefatos de contabilidade gerencial, tais como planejamento, $\mathrm{PMO}, \mathrm{BSC}$, hierarquização de projetos etc., e isto levou à geração de um artefato de alta complexidade. Esta condição deveria contribuir para a sua sedimentação, conforme é observado por Strang e Meyer (1993). Ressalta-se ainda que a decisão de implantação do GBV pela nova diretoria poderia ter ocorrido de forma não concorrente; o caminho seria a sua integração ao PGI, assim como o orçamento, conforme proposta do modelo teórico de Parisi (2011).

\subsection{Força causal "perda de patrocínio da alta direção"}

São apresentados os recortes das transcrições cuja análise levou à sua classificação no grupo do elemento "perda de patrocínio da alta direção":

- Entrevistado 1: Você sabe que todo instrumento de gestão, ferramenta de gestão, são fortemente dependentes do patrocínio do principal gerente.

- Entrevistado 2: O problema é a descontinuidade agora, porque na época [...]. Foi um envolvimento muito grande dos patrocinadores, da corporação, dos funcionários, da diretoria operacional como um todo...

- Entrevistado 3: E aí a nova direção que veio entrou com mais uma ferramenta de suporte, que é a gestão de agregar valor para o acionista [...]. Então assim, a gente deu mais importância para essa ferramenta específica do que para o planejamento.

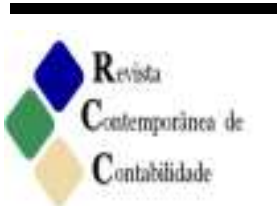


- Entrevistado 4: Então no finalzinho [...] desse mandato a gente estava conseguindo fazer essa união, entre desdobrar o PGI da EAE para as unidades, mas infelizmente com a mudança da direção a gente acabou parando...

Pode ser observada, nos trechos de discursos, a influência da perda de patrocínio da alta direção quando da mudança de diretoria, a qual decidiu por um novo artefato de contabilidade de gestão como suporte e retirou o apoio às práticas associadas ao PGI, sendo imperativo a desinstitucionalização do PGI. (TOLBERT; ZUCKER, 1999; DIMAGGIO; POWELL, 1983; LAWRENCE; WINN; JENNINGS, 2001)

\subsection{Força causal "ações que levam à descontinuidade do uso - desinstitucionalização"}

São apresentados os recortes das transcrições cuja análise levou à sua classificação no grupo do elemento "ações que levam à descontinuidade do uso - desinstitucionalização":

- Entrevistado 1: Então se o presidente não quer fazer as reuniões de avaliação da estratégia, ele não faz.

- Entrevistado 2: As reuniões de acompanhamento estratégico aconteciam pelo menos uma vez por mês nas reuniões dos superintendentes. [...] a análise crítica mostrava como estavam os indicadores. Hoje ainda é feita essa apresentação, mas não da forma que era. Era obrigatório constar isso em ata...

- Entrevistado 3: Nesse período de gestão o PGI foi pouco utilizado, mas nas gestões anteriores a cada 2 meses ou a cada 3 meses se fazia uma reunião de avaliação estratégica.

Podem ser observadas, nos trechos de discursos, ações que levam à descontinuidade do uso - desinstitucionalização. Pode-se observar que a interrupção da realização de práticas centrais associadas ao PGI, especificamente aquelas associadas à realização das reuniões de acompanhamento estratégico, contribuíram para a não sedimentação do PGI e para a sua desinstitucionalização, materializando a decisão da nova direção de não patrocinar mais este artefato (TOLBERT; ZUCKER, 1999; LAWRENCE; WINN; JENNINGS, 2001).

As demais forças percebidas e constantes da Tabela 3, cujos trechos de discursos não foram apresentados neste trabalho - apenas sua frequência foi computada - tiveram o mesmo tratamento, passando pelos mesmos procedimentos de análise.

\section{Considerações Finais}

O objetivo principal da pesquisa foi atingido, uma vez que foi possível conhecer um conjunto de 24 (vinte e quatro) elementos correlatos da Teoria Institucional, os quais atuam como forças causais do processo de institucionalização e desinstitucionalização do PGI da EAE. Entende-se que essas forças atuam no PGI e nos artefatos de contabilidade gerencial a ele associados em função de um conjunto de contradições e lógicas institucionais que oportunizam a ação humana através da práxis, como meio da materialização das mudanças sociais (POPIK; LAVARDA, 2015; SOEIRO; MIRANDA; ARAÚJO, 2016; SMETS; JARZABKOWSKI, 2013; WANDERLEY; SOEIRO, 2016).

Em decorrência da análise dos discursos foi possível identificar que o PGI se encontrava em um processo de desinstitucionalização, principalmente em função da perda do

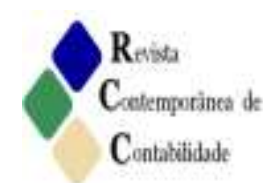


patrocínio da alta administração e do surgimento de um novo artefato que foi posicionado como concorrente do PGI. Identifica-se, ainda, que nos estágios de semi-institucionalização e total institucionalização estão presentes a maior parte das forças identificadas; entretanto, não é possível afirmar o estágio em que o PGI se encontra.

O objetivo secundário também foi atingido uma vez que a revisão teórica da NIS proporcionou elementos que possibilitaram desenvolver a Tabela 3, a partir da qual foi possível a associação dos elementos teóricos obtidos nas fontes bibliográficas com o contexto organizacional da concessionária estudada. Isto contribuiu para o entendimento de como acontecem os processos de institucionalização e desinstitucionalização de artefatos de contabilidade gerencial.

Quanto à resposta do problema de pesquisa, observa-se que na organização estudada foram identificados 24 (vinte e quatro) elementos correlatos da teoria institucional que atuam como força causal para o processo de institucionalização e desinstitucionalização. A identificação se deu por meio da análise de discurso sobre a percepção dos entrevistados a respeito da historicidade em que se deu a implantação do PGI, de seu contexto social, e das lógicas, racionalidades e contradições institucionais que oportunizam as ações humanas para a institucionalização e desinstitucionalização de práticas da contabilidade gerencial associadas ao PGI.

Do conjunto de forças observadas, 5 (cinco) foram percebidas pelos 4 (quatro) entrevistados, 3 (três) por 7 (sete) deles, 8 (oito) por 2 (dois) deles, e 4 (quatro) somente por 1 (um). Com base na lógica da saturação da amostra, apresentou-se a reflexão feita sobre as 12 (doze) percebidas por 3 (três) ou mais entrevistados, a fim de evidenciar o procedimento de reflexão realizado sobre o discurso do entrevistado e o cruzamento dos elementos textuais com a teoria, de modo a subsidiar a compreensão do surgimento das forças causais dos processos de institucionalização. Considera-se que a maior quantidade de percepções de diferentes atores confere maior confiança científica para a afirmação sobre a existência das forças; entretanto, com base no pensamento cientifico, também não é possível afirmar que as forças percebidas por uma menor quantidade simultânea de atores devam ser desconsideradas, podendo servir como pontos de partida para reflexões sobre outras naturezas de forças que possam impactar o contexto estudado. Desta forma, a pequena quantidade de respondentes pode ser considerada como uma limitação desta pesquisa, todavia não se pode desconsiderar as contribuições obtidas.

Com base neste procedimento foi possível responder à questão de pesquisa e conhecer as forças causais que são críticas para os processos de institucionalização e desinstitucionalização que agem sobre os artefatos de contabilidade gerencial em uma concessionária de serviços públicos que opera no Brasil.

A principal contribuição deste trabalho veio da possibilidade de estudar uma empresa de grande porte, de capital misto, de grande complexidade operacional, que nos anos 2000 desenvolveu e implantou um artefato customizado de planejamento integrando conceitos de diversos outros artefatos e práticas de gestão. Isto propiciou um ambiente repleto de contradições e lógicas institucionais, que oportunizou a possibilidade de ampliar o conhecimento sobre as variedades de classificações das possíveis forças causais críticas responsáveis pelos processos de institucionalização e desinstitucionalização que emergem da singularidade da visão de cada entrevistado, revelando aspectos teóricos relevantes que vão se confirmando à medida que novas entrevistas são analisadas e revelam os mesmos elementos que possibilitam a realização da inferência, tão importante no processo científico. 
Para futuras pesquisas sugere-se reaplicar este trabalho em ambientes de empresas multinacionais, empresas privadas e organizações sem fins lucrativos, a fim de se identificar os tipos de forças causais e, caso positivo, se elas ampliam o conjunto aqui apresentado.

\section{Referências}

ABRAHAMSON, Eric. Managerial fads and fashions: the diffusion and rejection of innovations. The Academy of Management Review, Biarcliff Manor, v.16, n.3, p.586-634, 1991.

BARDIN, Laurence. Análise de conteúdo. 3. ed. Lisboa: Edições 70, 2009.

BEUREN, Ilse Maria; RENGEL, Silene; RODRIGUES JUNIOR, Moacir Manuel. Relação dos atributos da contabilidade gerencial com os estágios do ciclo de vida organizacional. Revista Innovar, v.25, n.57, p.63-78, 2015. Disponível em: $<$ http://dx.doi.org/10.15446/innovar.v25n57.50328>. Acesso em: 20 jun. 2016.

BRIZOLLA, Maria Margarete Bacin et al. . Implantação do Balanced Scorecard (BSC) sob o enfoque da velha economia institucional em uma instituição de ensino superior do estado do RS. In: COLÓQUIO INTERNACIONAL DE GESTÃO UNIVERSITÁRIA; Desafios da Gestão Universitária no Século XXI, 15, 2015, Mar del Plata, Argentina. Recuperado em $7 / 7 / 16$ https://repositorio.ufsc.br/bitstream/handle/123456789/136036/101_00138.pdf?sequence=1\&i sAllowed $=\mathrm{y}$.

BURNS, John; SCAPENS, Robert W. Conceptualizing management accounting change: an institutional framework. Management Accounting Research, Manchester, v. 11, p.3-25, 2000.

CAREgNATO, Rita Catalina Aquino; MUTTI, Regina. Pesquisa qualitativa: análise de discurso versus análise de conteúdo. Texto Contexto Enfermagem, v.15, n.4, p.679-684, 2006.

CASAGRANDE, Rodrigo Moreira; LAVARDA, Carlos Eduardo Facin. Convergências teóricas entre a governança corporativa e a sustentabilidade sob a perspectiva da legitimidade. Revista de Gestão Social e Ambiental, São Paulo, v. 9, n. 2, p. 88-101, 2015.

CARVALHO, Cristina Amélia; VIEIRA, Marcelo Milano Falcão; SILVA, Sueli Maria Gulart. A trajetória conservadora da teoria institucional. Revista Eletrônica de Gestão organizacional, v.10, p. 460-496, 2012. Número especial.

CERVO, Armando Luiz; BERVIAN, Pedro Alcino. Metodologia científica. 5. ed. São Paulo: Prentice Hall, 2002.

COVALESKI, Mark A.; DIRSMITH, Mark W. An institutional perspective on the rise, social transformation, and fall of a University Budget Category. Administrative Science Quarterly, Ithaca, v.33, n.4, p.562-587, 1988. 
DIMAGGIO, Paul J.; POWELLL, Walter W. The iron cage revisited: institutional isomorphism and collective rationality in organizational fields. American Sociological Review, Albany, v.48 n.2, p. 147-160, 1983.

EBERLE, Veronica; COLAUTO, Romualdo Douglas. Pressões institucionais e adoção do Balanced Scorecard: o caso de uma organização do setor elétrico do sul do Brasil. Revista Contabilidade Vista \& Revista, UFMG, Belo Horizonte, v. 25, n. 3, p. 95-120, 2014.

FONTANELLA, Bruno J. B.; RICAS, Janete; TURATO, Egberto R. Amostragem por saturação em pesquisas qualitativas em saúde: contribuições teóricas. Caderno de Saúde Pública, Rio de Janeiro, v.24, n. 1, p. 17-27, 2008.

FREZATTI, Fabio; AGUIAR, Andson Braga; REZENDE, Amaury José. Respostas estratégicas às pressões institucionais e sucesso no atingir metas no orçamento: um estudo em uma empresa multinacional. Revista Organizações e Sociedades, Salvador, v.14, n.43, p.141-158, 2007.

FREZATTI, Fabio; BARROSO, Marcelo Francini Girão; CARTER, David B. Discursos internos se sustentam sem suporte da contabilidade gerencial? Um estudo de caso no setor de autopeças. Revista Organizações \& Sociedade, Salvador, v. 22, n.75, p. 485-504, 2015.

FREZATTI, Fabio; RELVAS, Tania Regina Sordi; JUNQUEIRA, Emanuel. BSC e a estrutura de atributos da contabilidade gerencial: uma análise no ambiente brasileiro. Revista de Administração de Empresas, v.50, n.2, p.187-198, 2010.

FREZATTI, Fabio. Críticas ao orçamento: Problemas com o artefato ou a não utilização de uma abordagem abrangente de análise? Advances in Scientific and Applied Accounting, v.3, n.2, p.190-216, 2010.

FRIEDLAND, Roger; ALFORD, Robert. R.. Bringing society back in: Symbols, practices, and institutional contradictions. In POWELL, Walter W.; DIMAGGIO. Paul J. (Eds.). The new institutionalism in organizational analysis (Chap. 10, pp. 232-266). Chicago: Chicago University Press. 1991.

GODOI, Christiane Kleinubing. Perspectiva de análise do discurso nos estudos organizacionais. In: GODOI, Christiane Kleinubing; BANDEIRA-DE-MELLO, Rodrigo; SILVA, Anielson Barbosa da. Pesquisa qualitativa em estudos organizacionais: paradigmas, estratégias e métodos. 2. ed. São Paulo: Saraiva, 2010.

GUERREIRO, Marta Silva; RODRIGUES, Lucia Lima; CRAIG, Russell. Voluntary adoption of international financial reporting standards by large unlisted companies in Portugal institutional logics and strategic responses. Accounting, Organizations and Society, v.37, p.482-499, 2012.

GUERREIRO, Reinaldo; CORNACHIONE JUNIOR, Edgard Bruno; SOUTES, Dione Olesczuk. Empresas que se destacam pela qualidade das informações a seus usuários externos também se destacam pela utilização de artefatos modernos de contabilidade gerencial? Revista Contabilidade \& Finanças, v. 22, n.55, p. 88-113, 2011. Disponível em: $<$ http://dx.doi.org/10.1590/S1519-70772011000100006>. Acesso em: 20 jun. 2016.

GUERREIRO, Reinaldo; FREZATTI, Fabio; CASADO, Tânia. Em busca de um melhor entendimento da contabilidade gerencial através da integração de conceitos de psicologia, 
cultura organizacional e teoria institucional. Revista Contabilidade e Finanças, USP, São Paulo, p. 7-21, 2006. Edição comemorativa. Disponível em: $<$ http://dx.doi.org/10.1590/S1519-70772006000400002>. Acesso em: 05 maio 2009.

GUERREIRO, Reinaldo; PEREIRA, Carlos Alberto; FREZATTI, Fabio. Aplicação do modelo de Burns e Scapens para avaliação do processo de institucionalização da contabilidade gerencial. Revista Organizações e Sociedades, Salvador, v.15, n.44, p. 45-62, 2008. Disponível em: <http://dx.doi.org/10.1590/S1984-92302008000100003.1590/S198492302008000100003 >. Acesso em: 18 jan. 2010.

GUERREIRO, Reinaldo. O entendimento da contabilidade gerencial sob a ótica da teoria institucional. Revista Organizações e Sociedades, v.12, n.35, p. 91-106, out./dez. 2005.

INTERNATIONAL FEDERATION OF ACCOUNTANTS (IFAC). International management accounting practice statement: management accounting concepts, mar. 1998.

ITTNER, Christopher; LARCKER, David; MEYER, Marshall. Subjectivity and weighing of performance measures: evidence from a balanced scorecard. The Accounting Review, Austin, v.3, n.78, p.725-758, 2003.

JONES, Candace; RAEY, Trish. Qualitatively capturing institutional logics. Strategic Organization, $p .1-14,2015$. Disponível em: < DOI: $10.1177 / 1476127015589981>$. Acesso em: 25 jun. 2016.

LAWRENCE, Thomas B.; WINN, Monika I.; JENNINGS, P. Devereaux. The temporal dynamics of institutionalization. The Academy of Management Review, Biarcliff Manor, v.26, n.4, p.624-644, 2001.

LOUNSBURY, Michael; BOXENBAUM, Eva. Institutional logics in action (Part A). Research in the Sociology of Organizations, v. 39A, p. 3-22, 2013.

MEYER, John W.; ROWAN, Brian. Institutionalized organizations: formal structure as myth and ceremony. American Journal of Sociology, Chicago, v.83, n.2, p.340-363, 1977.

MEYER, John W.; SCOTT, Richard; STRANG, David. Centralization, fragmentation, and school district complexity. Administrative Science Quarterly, Ithaca, v.32, n.2, p.186-201, 1987.

OYADOMARI, José Carlos Tiomatsu et al. Fatores que influenciam a adoção de artefatos de controle gerencial nas empresas brasileiras. Um estudo exploratório sob a ótica da teoria institucional. Revista de Contabilidade e Organizações, v.2, n.2, p. 55-70, 2008.

PARISI; Claudio. Capítulo 5 - Planejamento e Controle. In: Contabilidade Gerencial. PARISI, Claudio; MEGLIORINI, Evandir. São Paulo: Atlas, 2011.

POPIK, Fabiane; LAVARDA, Carlos Eduardo Facin. Contradições institucionais, práxis e mudança do controle gerencial: estudo de caso em uma cooperativa. In: CONGRESSO BRASILEIRO DE CUSTOS, 21., 2015, Anais..., Foz do Iguaçu.

REIS, Luciano Gomes. A influência do discurso no processo de mudança da contabilidade gerencial: um estudo de caso sob o enfoque da teoria institucional. 2008. Tese 
(Doutorado em Ciências Contábeis) - Programa de Pós-Graduação em Ciências Contábeis, Faculdade de Economia, Administração e Contabilidade, Universidade de São Paulo, São Paulo.

REZENDE, Amaury José. Um estudo sobre o processo de desinstitucionalização das práticas contábeis de correção monetária em empresas brasileiras. 2009. Tese (Doutorado em Ciências Contábeis) - Programa de Pós-Graduação em Ciências Contábeis, Faculdade de Economia, Administração e Contabilidade, Universidade de São Paulo, São Paulo.

RODRIGUES, Sergio Ricardo. Adoção e implementação de centro de serviços compartilhados sob a óptica da teoria institucional: $O$ caso de um grupo de serviços de tecnologia da informação. 2016. Dissertação (Mestrado em Controladoria Empresarial) Programa de Pós-Graduação em Ciências Contábeis, Universidade Presbiteriana Mackenzie, São Paulo.

ROWAN, Brian. Organizational structure and the institutional environment: the case of public schools. Administrative Science Quarterly, Ithaca, v.27, n.2, p.259-279, 1982.

RUSSO, Paschoal Tadeu. O comportamento do uso de práticas de contabilidade gerencial sob a ótica institucional. 2015. Tese (Doutorado em Controladoria e Contabilidade) Programa de Pós-Graduação em Controladoria e Contabilidade, Universidade de São Paulo, São Paulo.

RUSSO, Paschoal Tadeu et al. Evidências de elementos de institucionalização do Balanced Scorecard na obra "A estratégia em ação": um olhar baseado na teoria institucional. Revista de Contabilidade e Finanças da USP. São Paulo, v.23, n.58, p.7-18, 2012.

SCOTT, W. Richard. Institutions and organizations. 2. ed. Thousand Oaks, California: Sage Pub, 2001.

SELZNICK, Philip. Institutionalism "old" and "new". Administrative Science Quarterly, Ithaca, v.41, n.2, p.270-277, 1996.

SEO, Myeong-Gu; CREED, W. E. Douglas. Institutional contradictions, praxis, and institutional change: a dialetical perspective. Academy of Management Review, v.27, n.2, p.222-247, 2002.

SMETS, Michael; JARZABKOWSKI, Paula. Reconstructing institutional complexity in practice: a relational model of institutional work and complexity. Human Relations, v. 66, p.1279-1309, 2013. Disponível em: < http://dx.doi.org/10.1177/0018726712471407>. Acesso em: 03 jul. 2016.

SOEIRO, Tiago de Moura; MIRANDA, Luiz Carlos; ARAÚJO, João Gabriel Nascimento. Contradição institucional e mudança na alta administração: o caso de uma empresa nordestina de tecnologia de informação. Revista Universo Contábil, Blumenau, v. 12, n. 1, p. 162-177, 2016. Disponível em: < http://dx.doi.org/10.4270/ruc.2016109>. Acesso em: 03 jul. 2016.

SOUTES, Dione Olesczuk. Uma investigação do uso de artefatos da contabilidade gerencial por empresas brasileiras. 2006. Dissertação (Mestrado em Ciências Contábeis) Programa de Pós-Graduação em Controladoria e Contabilidade, Universidade de São Paulo, São Paulo. 
STEEN, Martijn van der. Human agency in management accounting change: a cognitive approach to institutional theory. The Netherlands: Labyrinth Publications, 2005.

STRANG, David; MEYER, John W. Institutional conditions for diffusion. Theory and Society, Dordrecht, v.22, n.4, p.487-511, 1993.

SVENNINGSEN, Virginie; BOXENBAUM, Eva; RAVASI, Davide. How individuals cope with institutional complexity in organizations: a case study in the energy transition. In: EGOS COLLOQUIUM, 32., 2016, Naples, Italy.

THORNTON, Patricia H.; JONES, Candace; KURY, Kenneth. Institutional logics and institutional change in organizations: transformation in accounting, architecture, and publishing. Research in the Sociology of Organizations, v. 23, p.125-170, 2005.

TOLBERT, Pamela S.; ZUCKER, Lynne G. Institutional sources of change in the formal structure of organizations: the diffusion of civil service reform, 1880-1935. Administrative Science Quarterly, Ithaca, v.28, n.1, p.22-39, 1983.

TOLBERT, Pamela S.; ZUCKER, Lynne G. A institucionalização da teoria institucional. In: CLEGG, Stewart R.; HARDY, Cynthia; NORDY, Walter R. Handbook de estudos organizacionais. Tradução de H. F. Martins e R. L. S. Cardoso. São Paulo: Atlas, 1999. v.1, p.196-219.

WANDERLEY, Claudio de Araújo; SOEIRO, Tiago de Moura. Contradição institucional e o Balanced Scorecard: um caso de mudança sem sucesso. Revista Universo Contábil, Blumenau, v. 12, n. 1, p. 45-65, 2016. Disponível em: $<$ http://dx.doi.org/10.4270/ruc.2016103>. Acesso em: 03 jul. 2016.

WRUBEL, Franciele; TOIGO, Leandro Augusto; LAVARDA, Carlos Eduardo Facin. Mudanças nas rotinas contábeis: contradições institucionais e práxis humanas. In: CONGRESSO NACIONAL DE ADMINISTRAÇÃO E CIÊNCIAS CONTÁBEIS, 5., 2014, Rio de Janeiro, Anais..., 2014.

ZAN, Adriano. Mudanças da contabilidade gerencial de uma organização: estudo de caso com diagnóstico institucional. 2006. Dissertação (Mestrado em Ciências Contábeis) Programa de Pós-Graduação em Ciências Contábeis, Faculdade de Economia, Administração e Contabilidade, Universidade de São Paulo, São Paulo.

ZUCKER, Lynne G. The role of institutionalization in cultural persistence. American Sociological Review, Albany, v.42, n.5, p.726-743, 1977.

ZUCKER, Lynne G. Institutional theories of organization. Anual Review of Sociology, Palo Alto, v.13, p.443-464, 1987. 